\title{
Memoria de actividades de la Cátedra de Hidrología Médica - Escuela Profesional de Hidrología Médica e Hidroterapia: 2000 - 2012
}

\author{
Francisco MARAVER EYZAGUIRRE ${ }^{(1-2)}$ \\ (1) Escuela Profesional de Hidrología Médica e Hidroterapia. Facultad de Medicina. \\ Universidad Complutense de Madrid. Plaza Ramón y Cajal s/n, 28040 Madrid (España). \\ (2) Departamento Medicina Física y Rehabilitación. Hidrología Médica. \\ Facultad de Medicina. Universidad Complutense de Madrid. Plaza Ramón y Cajal s/n, \\ 28040 Madrid (España). \\ fmaraver@med.ucm.es
}

\section{Resumen}

El presente trabajo reúne las principales acciones desarrolladas por la Cátedra de Hidrología Médica y Escuela Profesional de Hidrología Médica e Hidroterapia de la Facultad de Medicina de la Universidad Complutense de Madrid en los últimos doce años, período que coincide en el tiempo con el de la gestión de su actual Junta Directiva.

Durante esta etapa, se ha adaptado la disciplina al espacio europeo de educación superior, incorporándola también a la formación de grado en distintas titulaciones; se ha promovido las relaciones institucionalizadas con relevantes organismos a nivel nacional e internacional, en Europa e Iberoamérica y se ha dotado de órganos de expresión propio fundando los Anales de Hidrología Médica y la serie de monografías Balnea.

La memoria se estructura en tres partes: 1) dedicada a la actividad docente desarrollada tanto en la propia Universidad Complutense, como en otras Universidades e Instituciones; 2) dedicada a la actividad investigadora que se divide a su vez en cuatro apartados, el primero, refleja los proyectos financiado en convocatorias públicas así como los contratos con empresas ó administraciones, el segundo, incluye las publicaciones de libros, capítulos de libros y en revistas científicas nacionales e internacionales, el tercero, contiene las contribuciones a congresos y el cuarto, anota la relación de trabajos académicos dirigidos, y 3) dedicada otras actividades.

Palabras clave: Cátedra de Hidrología Médica, Escuela Profesional de Hidrología Médica e Hidroterapia, Especialidad en Ciencias de la Salud, Formación sanitaria especializada, Profesión sanitaria, Medicina Termal, Hidrología Médica, Formación de especialistas 


\title{
Activity Report of the Chair of Medical Hydrology - Professional School of Medical Hydrology and Hydrotherapy: 2000 - 2012
}

\begin{abstract}
This paper summarizes the main actions developed by the Chair of Medical Hydrology and Professional School of Medical Hydrology and Hydrotherapy of the Faculty of Medicine, Complutense University of Madrid, in the last twelve years under the management of its current Board

During this stage, the discipline has been adapted to European education area for college degrees, including the introduction of undergraduate training at different levels; institutional relationships with relevant national and international agencies have been promoted, both with Europe and with Latin America; and specific journals such as Anales de Hidrología Médica and the monographs Balnea have begun their introduction in this field.

The memory is divided into three parts: 1) dedicated to the teaching aspects developed both within the Complutense University, as well as, in other Universities and Institutions; 2) dedicated to research which is divided into four sections: the first reflects the projects funded by public contracts and others with private companies or administrations, the second includes the publication of books, chapters in books or in national and international scientific journals, the third contains contributions to congress and the fourth consists of a list of academic papers supervised by the chair and 3) other related activities
\end{abstract}

Key words: Chair of Medical Hydrology, Professional School of Medical Hydrology and Hydrotherapy, Health Science Speciality, Specialized Sanitary Education, Health Profession, Health Resort Medicine, Medical Hydrology, Specialist Training

\section{REFERENCIA NORMALIZADA}

Maraver F. Memoria de actividades de la Cátedra de Hidrología Médica - Escuela Profesional de Hidrología Médica e Hidroterapia: 2000 - 2012 (Activity Report of the Chair of Medical Hydrology Professional School of Medical Hydrology and Hydrotherapy: 2000 - 2012). Balnea, 2012, 7, 183-261. 
ACTIVIDAD DOCENTE

UNIVERSIDAD COMPLUTENSE DE MADRID

FACULTAD DE MEDICINA

$\underline{\text { PRE-GRADO }}$

\section{Licenciatura de Medicina}

\section{Hidrología y Climatología Médica}

Asignatura Optativa 4,5 créditos

Cursos Académicos: 2000-01, 2001-02, 2002-03, 2003-04, 2004-05, 2005-06, 2006-07, 2007-08, 2008-09, 2009-10, 2010-11, 2011-12

\section{Diplomatura de Terapia Ocupacional}

Técnicas Asociadas para Terapia Ocupacional

Asignatura Optativa 4,5 créditos

Cursos Académicos: 2002-03, 2003-04, 2004-05, 2005-06, 2006-07, 2007-08, 2008-09, 2009-10, 2010-11, 2011-12

\section{Diplomatura de Nutrición}

Aguas minerales envasadas en nutrición y dietética

Asignatura Libre Elección Genérica 4,5 créditos

Cursos Académicos: 2003-04, 2004-05, 2005-06, 2006-07, 2007-08, 2008-09, 2009-10, 2010-11

\section{$\underline{\text { Grado de Medicina }}$}

Hidrología y Climatología Médica

Asignatura Optativa 3 ECTS

Cursos Académicos: 2010-11, 2011-12

$\underline{\text { POST-GRADO }}$

Programa de Doctorado: HIDROLOGÍA MÉDICA

Metodología aplicada a la Hidrología Médica

Curso Metodológico 3 créditos

Introducción a la Hidrología Médica. Aguas mineromedicinales. Características y Acciones

Curso Fundamental 3 créditos 
Análisis de las aguas minero medicinales y minerales naturales

Curso Fundamental 3 créditos

Indicaciones y contraindicaciones de las aguas minero medicinales y minerales naturales

Curso Fundamental 3 créditos

Técnicas crenoterapia. Instalaciones termales

Curso Fundamental 3 créditos

Ambiente balneario. Climatoterapia. Helioterapia Talasoterapia

Curso Fundamental 3 créditos

Hidroterapia - Hidrocinesiterapia

Curso Fundamental 3 créditos

Cursos Académicos: 2000-01, 2001-02, 2002-03, 2003-04, 2004-05, 2005-06, 2006-07, 2007-08, 2008-09

\section{Cursos de Formación de Médicos Especialistas en: HIDROLOGÍA MÉDICA}

Plan de Estudios 1988 (BOE 1988;220:27074-27076), acceso vía MIR

$1^{\circ}$ Año: Hidrología Médica 30 créditos

$\mathbf{2}^{\circ}$ Año: Hidroterapia 18 créditos

Cursos Académicos: 2000-01, 2001-02, 2002-03, 2003-04, 2004-05, 2005-06, 2006-07, 2007-08, 2008-09, 2009-10, 2010-11, 2011-12

\section{TÍTULOS PROPIOS - CONVENIOS ESPECÍFICOS}

Curso "Legionella y balnearios"

UCM-ISCIII-ANET. 11-13/03/2003

Curso "Terapéutica con agua marina"

UCM. 06-08/06/2005

Curso "Medicina estética hidrotermal"

UCM-ISCIII-ANET. 14-17/12/2005

Curso "Terapéutica con agua marina"

UCM. 01-03/02/2006

III Curso de Especialista Universitario en "Medicina Estética y Cosmética" UCM. 10/01/2009 
FACULTAD DE VETERINARIA

$\underline{\text { PRE-GRADO }}$

$\underline{\text { Licenciatura de Ciencia y Tecnología de los Alimentos }}$

Aguas de consumo Mineromedicinales

Asignatura Optativa 6 créditos

Cursos Académicos: 2000-01, 2001-02, 2002-03, 2003-04, 2004-05, 2005-06, 2006-07, 2007-08, 2008-09, 2009-10, 2010-11, 2011-12

FACULTAD DE ENFERMERÍA, PODOLOGÍA Y FISIOTERAPIA

$\underline{\text { PRE-GRADO }}$

Diplomatura de Fisioterapia

Balneoterapia y Talasoclimatoterapia

Asignatura Libre Elección $\quad 4,5$ créditos

Cursos Académicos: 2004-05, 2006-07, 2007-08, 2008-09

\section{Grado de Fisioterapia}

Procedimientos Generales I: (Balneoterapia - Masoterapia)

Asignatura Obligatoria6 ECTS $(3+3)$

Cursos Académicos: 2010-11, 2011-12

\section{OTRAS UNIVERSIDADES}

UNIVERSIDAD DE GRANADA

1. Curso de verano: "El Turismo de salud en la Sociedad actual". Lanjarón (Granada) 17-21/07/2000.

- Codirección del Curso:

- Ponencias invitadas:

Turismo de Salud: conceptos y situación actual

La Talasoterapia y Tratamientos Marinos

Mesa redonda: debate sobre los temas del curso 
UNIVERSIDAD DE LA CORUÑA

2. Curso monográfico del doctorado: "Significación del Termalismo en Galicia". Arnoia (Ourense) 06-07/04/2001.

- Ponencia invitada:

Situación actual de la investigación en termalismo y aguas envasadas

UNIVERSIDAD DE LA CORUÑA

3. Curso monográfico del doctorado: "Significación del Termalismo en Galicia". La Toja (Pontevedra) 01-02/03/2002.

- Ponencia invitada:

Sistemas de calidad en centros termales

UNIVERSIDAD DE ZARAGOZA

4. Título propio: "Curso de Postgrado de Medicina Naturista". Zaragoza 0809/03/2002.

- Ponencia invitada:

Sistemas de calidad en centros termales

UNIVERSIDAD DE VALLADOLID

5. Título propio: "V Curso de Especialización en Balneoterapia". Soria 0512/04/2002.

- Ponencias invitadas:

El agua y su estructura

Propiedades fisico-químicas del agua

Análisis del agua

Análisis del agua

Aguas madres

Climatoterapia

Helioterapia

Talasoterapia

\section{UNIVERSIDAD DE GRANADA}

6. Curso de verano: "Medicina estética termal”. Lanjarón (Granada) 15-19/07/2002.

- Codirección del Curso:

- Ponencias invitadas:

Medicina Estética Termal: conceptos y situación actual

Crenoterapia en afecciones Dermatológicas

El Balneario de Lanjarón y la Estética Termal. Las aguas mineromedicinales del Balneario de Lanjarón en Dermatología 
UNIVERSIDAD DE VIGO

7. Master en: “Organización y Dirección Turística”. Ourense 19/06/2003.

- Ponencia invitada:

Aguas envasadas y Termalismo

UNIVERSIDAD DE ZARAGOZA

8. Título propio: “Curso de Postgrado de Medicina Naturista”. Zaragoza 30/01/2004.

- Ponencias invitadas:

Aguas envasadas

Sistemas de calidad en centros termales

UNIVERSIDAD DE VIGO

9. Master en: “Organización y Dirección Turística”. Ourense 08/07/2004.

- Ponencia invitada:

Aguas envasadas

UNIVERSIDAD DE ZARAGOZA

10. Curso de verano: "Actualidad en aguas minero-medicinales y minerales naturales y balnearios". Teruel 19/07/2004.

- Ponencias invitadas:

Aguas envasadas

Análisis de aguas mineromedicinales

UNIVERSIDAD DE GRANADA

11. Curso de verano: "Legionella Balnearios". Lanjarón (Granada) 19-23/07/2004.

- Codirección del Curso:

- Ponencias invitadas:

Instalaciones Crenoterápicas

Usuarios de un Balneario

UNIVERSIDAD DEL PAÍS VASCO

12. XXIII Seminario de la APURF. Bilbao 26-28/05/2005.

- Ponencia invitada:

Las Competencias profesionales en Radiología y Medicina Física y la adecuación en el Espacio Europeo de Enseñanza Superior 
UNIVERSIDAD DE VIGO

13. Master en: "Organización y Dirección Turística”. Ourense 29/07/2005.

- Ponencia invitada:

Aguas envasadas

UNIVERSIDAD NACIONAL DE ENTRE RÍOS - ARGENTINA

14. Carrera de especialización en Termalismo: Módulo "Balneología I". Concordia (Entre Ríos - Argentina) 23-24/09/2005.

- Docente responsable:

- Ponencias invitadas:

Presentación

Mecanismo de acción de las aguas mineromedicinales

Aguas envasadas

Balneotécnicas

Indicaciones de las aguas mineromedicinales

Contraindicaciones de las aguas mineromedicinales

Climatología marina

Talasoterapia

Técnicas atmiátricas

Marketing sanitario termal

\section{UNIVERSIDAD DE LA CORUÑA}

15. Curso monográfico del doctorado: "Significación del Termalismo en Galicia". Guitiriz (Lugo) 17-18/03/2006.

- Ponencias invitadas:

Presentación

Aguas en bebida

\section{UNIVERSIDAD DE GRANADA}

16. Curso de verano: "Establecimientos balnearios: historia, literatura y medicina". Lanjarón (Granada) 17-21/07/2006.

- Codirección del Curso:

- Ponencias invitadas:

Roma y las Termas: vestigios en Hispania

El Balneario de Lanjarón y su evolución sanitaria

Balnearios y Manantiales del Pirineo Aragonés a través de los viajeros 
UNIVERSIDAD DE CADIZ

17. Máster de gestión de la calidad en el sector turístico. Jerez de la Frontera (Cádiz) 15/02/2007.

- Ponencias invitadas:

Turismo de Salud: consideraciones generales

Turismo de Salud: sistemas de calidad

Turismo de Salud: marketing sanitario termal

Aguas envasadas

\section{UNIVERSIDAD DE SANTIAGO}

18. Curso de verano: "Hidratación, nutrición e saúde". Lugo 16-20/07/2007.

- Ponencias invitadas:

Auga: clasificación e tipos

Auga e balneoterapia

\section{UNIVERSIDAD NACIONAL DE ENTRE RÍOS - ARGENTINA}

19. Seminario Internacional: "Termalismo y Tipos de Aguas Termales". Buenos Aires (Argentina) 10-11/08/2007.

- Ponencias invitadas:

Presentación

Antecedentes

Mecanismo de acción de las aguas

Aguas envasadas

Hidroleptología

Protocolo de Peloides

UNIVERSIDAD DE NAVARRA

20. Curso de verano: “Medicamentos, Placebos y Fraudes”. Pamplona 10-12/09/2007.

- Ponencia invitada:

Hidroterapia: el remedio del mundo antiguo

UNIVERSIDAD DE CANTABRIA

21. Curso monográfico del doctorado: "Los Balnearios como Agentes Terapéuticos". Santander 04-12/04/2008.

- Ponencias invitadas:

La Cura Balnearia en las Enfermedades del Aparato Génito-Urinario

La Cura Termal en las Afecciones Digestivas, Metabólicas y Endocrinas Aguas Evasadas

Los Balnearios en España 
UNIVERSIDAD DE LA CORUÑA

22. Curso monográfico del doctorado: "Significación del Termalismo en Galicia". La Coruña 22-23/05/2008.

- Ponencia invitada:

Mecanismos de acción da terapia termal. Indicacións terapéuticas, contraindicacións. Principais balnearios españois

UNIVERSIDAD DE GRANADA

23. Curso de verano: “Agua, hidratación y salud”. Lanjarón (Granada) 14-18/07/2008.

- Codirección del Curso:

- Ponencias invitadas:

Agua: clasificación y tipos

Cata de aguas Mineromedicinales y Minerales Naturales de Lanjarón

Requerimientos hídricos de los deportistas

UNIVERSIDAD NACIONAL DE ENTRE RÍOS - ARGENTINA

24. Seminario Internacional: "Avances en Hidrología Médica \&Termalismo”. Buenos Aires (Argentina) 24-25/10/2008.

- Ponencias invitadas:

Gestión de la Calidad en Termalismo

Aguas bicarbonatadas e Hipertensión

Termalismo y Laboratorio: aguas y fangos

Aguas Minerales Envasadas

Indicaciones actuales del Termalismo

\section{UNIVERSIDAD DE LA CORUÑA}

25. Curso monográfico del doctorado: "Bases clínicas e investigación en terapéutica termal". La Coruña 28-29/05/2009.

- Ponencia invitada:

Mecanismos de acción da terapia termal. Indicacións terapéuticas, contraindicacións. Principais balnearios españois

UNIVERSIDAD DE MURCIA

26. V Ciclo: "Hábitos para un envejecimiento saludable". Murcia 30/11/2010.

- Ponencia invitada: Aguas Minerales naturales envasadas y Personas Mayores 
UNIVERSIDAD INTERACIONAL MENENDEZ PELAYO

27. XII Seminario: "Nutrición y alimentación. Elecciones diarias con impacto en la salud". Cuenca 06-07/10/2011.

- Ponencia invitada:

¿Es lo mismo el agua del grifo que el agua envasada? No, sin duda, no

UNIVERSIDAD DE GRANADA

28. Ciclo de Conferencias y Reuniones Científicas: "Recursos naturales y salud humana". Granada 22-23/03/2012.

- Ponencia invitada:

Una vieja terapia cada día más joven: Aguas minerales y mineromedicinales. Su aplicación balnearia

\section{OTRAS INSTITUCIONES}

\section{ESCUELA NACIONAL DE SANIDAD (ISCIII) - MINISTERIO DE SANIDAD Y CONSUMO}

1. Máster en Gestión Sociosanitaria: Módulo "Aspectos Sociosanitarios del Termalismo". Madrid 13-14/12/2001.

- Ponencias invitadas:

Presentación. Situación actual del Sector Termal en España. Marco legal

Las aguas mineromedicinales: origen, tipos y mecanismo de acción

Termalismo Social

Vías y Técnicas de administración de las aguas: crenoterapia, hidroterapia y talasoterapia

Termalismo y tercera edad

Control de calidad de los servicios Termales

\section{IMSERSO - MINISTERIO DE TRABAJO Y ASUNTOS SOCIALES}

2. Curso de: "Conocimientos básicos sobre el tratamiento termal". Madrid 2021/05/2003.

- Ponencias invitadas:

Nociones sobre fisica y química del agua

Mecanismo de acción de aguas mineromedicinales

Técnicas de tratamiento en balnearios

Indicaciones de las aguas mineromedicinales

Principales contraindicaciones al tratamiento termal 
JUNTA DE ANDALUCÍA - CENTRO DE PROFESORADO DE CÁDIZ

3. Curso de: "Estética hidrotermal". Jerez de la Frontera 30-04/06-07/2003.

- Ponencias invitadas:

Instalaciones balnearias en España Propiedades de sus aguas y empleo en Hidrología Médica

Mecanismo de acción de las aguas mineromedicinales

ESCUELA NACIONAL DE SANIDAD (ISCIII) - MINISTERIO DE SANIDAD Y CONSUMO

4. Master en Gestión Sociosanitaria: Módulo "Aspectos Sociosanitarios del Termalismo". Madrid 06-10/10/2003.

- Ponencias invitadas:

Situación actual del Sector Termal en España. Marco legal

Aspectos Sociosanitarios del Termalismo

Las aguas mineromedicinales: origen, tipos y mecanismo de acción

Termalismo Social

IMSERSO - MINISTERIO DE TRABAJO Y ASUNTOS SOCIALES

5. Curso de: "Conocimientos básicos sobre el tratamiento termal". Madrid 13$17 / 10 / 2003$.

- Ponencias invitadas:

Nociones sobre física y química del agua

Mecanismo de acción de aguas mineromedicinales

Técnicas de tratamiento en balnearios

Indicaciones de las aguas mineromedicinales

Principales contraindicaciones al tratamiento termal

\section{COLEGIO DE ARQUITECTOS DE CATALUÑA}

6. XXVI Cursillo sobre la intervención en el Patrimonio Arquitectónico: "Balnearios. El patrimonio termal". Barcelona 11-14/12/2003.

- Ponencias invitadas:

Hidrología Médica. Establecimientos balnearios hoy

CENTRO NACIONAL DE MICROBIOLOGÍA (ISCIII) - MINISTERIO DE SANIDAD Y CONSUMO

7. III Curso "Prevención de Legionelosis". Madrid 21-24/06/2004.

- Ponencia invitada:

Prevención y control de legionelosis en Balnearios 
JUNTA DE CASTILLA Y LEÓN - CONSEJERÍA DE SANIDAD

8. Curso: "Módulo de epidemiología especial: Epidemiología de las enfermedades infecciosas y la interpretación epidemiológica de los resultados de laboratorio. Estudio especial de tuberculosis y legionelosis". Medina del Campo 15-17 y 01-03/11 y $12 / 2004$.

- Ponencia invitada:

Prevención y control de legionelosis en Balnearios

IMSERSO - MINISTERIO DE TRABAJO Y ASUNTOS SOCIALES

9. Curso de: "Conocimientos básicos sobre el tratamiento termal". Madrid 0307/10/2005.

- Ponencias invitadas:

Balnearios otros Centros de Salud

Mecanismo de acción de aguas mineromedicinales

Técnicas de tratamiento en balnearios

Indicaciones de las aguas mineromedicinales

JUNTA DE ANDALUCÍA - CENTRO DEL PROFESORADO DE MOTRIL

10. I Curso multidisciplinar sobre la cultura del agua: "Aproximación al agua en su marco natural”. Lanjarón (Granada) 28-01/08-09/2006.

- Ponencia invitada:

Balneoterapia e Hidroterapia

SEMERGEN

11. Primer Curso: “Osteoporosis en Atención Primaria". Lanjarón (Granada) 03/02/2007.

- Ponencia invitada:

Osteoporosis, ejercicio fisico y Balneoterapia

JUNTA DE ANDALUCÍA - CENTRO DE PROFESORADO DE GRANADA

12. Curso de: "Perfeccionamiento en Estética hidrotermal". Lanjarón (Granada) 0206/07/2007.

- Ponencias invitadas:

Instalaciones balnearias en España. Propiedades de sus aguas y empleo en hidrología médica

Las aguas mineromedicinales del Balneario de Lanjarón. Propiedades y empleo 
JUNTA DE ANDALUCÍA - CENTRO DEL PROFESORADO DE MOTRIL

13. II Curso multidisciplinar sobre la cultura del agua: "Los paisajes del agua". Lanjarón (Granada) 27-31/08/2007.

- Ponencia invitada:

Historia del Balneario de Lanjarón

JUNTA DE ANDALUCÍA - CENTRO DEL PROFESORADO DE MOTRIL

14. III Curso multidisciplinar sobre la cultura del agua: "Jugar con agua". Lanjarón (Granada) 25-29/08/2008.

- Ponencia invitada:

Balneario y Agua, Antecedentes

JUNTA DE ANDALUCÍA - CENTRO DEL PROFESORADO DE MOTRIL

15. IV Curso multidisciplinar sobre la cultura del agua: "Agua y vino". Lanjarón (Granada) 24-28/08/2009.

- Ponencia invitada:

Los balneario, el agua y el vino

JUNTA DE ANDALUCÍA - CENTRO DEL PROFESORADO DE MOTRIL

16. V Curso multidisciplinar sobre la cultura del agua: "Bendita agua". Lanjarón (Granada) 23-27/08/2010.

- Ponencia invitada: Aguas termales y mistica

JUNTA DE ANDALUCÍA - CENTRO DEL PROFESORADO DE MOTRIL

17. VI Curso multidisciplinar sobre la cultura del agua: "Agua del cielo no quita riego". Lanjarón (Granada) 22-26/08/2011.

- Ponencia invitada:

Termalismo y cielos

JUNTA DE ANDALUCÍA - CENTRO DEL PROFESORADO DE MOTRIL

18. VII Curso multidisciplinar sobre la cultura del agua: "Caminos de Agua...". Lanjarón (Granada) 27-31/08/2012.

- Ponencia invitada:

Viajes de agua. Balnearios y manantiales de Granada a través de viajeros e hidrólogos 
EXPOURENSE - TERMATALIA PERÚ

19. Seminario: "Agua y Salud".

El Callao - Lima (Perú) 29/09/2012.

- Ponencias invitadas:

Consideraciones Generales

Balneología, Balneoterapia, Crenoterapia, Cura Termal ó Cura Balnearia

Hidroterapia

Talasoterapia

Aguas Envasadas

Términos de búsqueda en MEDLINE/PubMed en el MeSH

Investigación científica en Termalismo

\section{ACTIVIDAD INVESTIGADORA}

\section{PROYECTOS FINANCIADOS EN CONVOCATORIAS PÚBLICAS}

1. Título: POSTGRADO EN TERMALISMO E HIDROLOGÍA MÉDICA

Entidad financiadora: AECI-Programa Cooperación Interuniversitaria e Investigación Científica（ref. AECI B-6262-06)

Duración desde: $2007 \quad$ hasta: 2007

2. Título: POSTGRADO EN TERMALISMO E HIDROLOGÍA MÉDICA

Entidad financiadora: AECI-Programa Cooperación Interuniversitaria e Investigación Científica (ref. AECI B-010615-07)

Duración desde: 2008 hasta: 2008

3. Título: DETERMINACIÓN DE PROPIEDADES TERAPÉUTICAS DE MEZCLAS Y PELOIDES PARA SU APLICACIÓN EN BALNEARIOS Y TALASOS

Entidad financiadora: MCIN-Subprograma de Proyectos de Investigación Fundamental Orientada a la Transmisión del Conocimiento (ref. TRA20090240-02)

Duración desde: 2010 hasta: 2012

4. Título: ESTUDIO DE LOS CAMBIOS BIOLÓGICOS Y PROPIEDADES TERAPEUTICAS DURANTE EL PROCESO DE MADURACIÓN DE PELOIDES DE BALNEARIOS Y TALASOS GALLEGOS

Entidad financiadora: Xunta de Galicia-Programa de promocion xeral de investigación (ref. 10 PXIB 137153 PR)

Duración desde: $2010 \quad$ hasta: 2013 
5. Título: PROYECTO BALNEARIOS: I. EL TEJIDO BALNEARIO DURANTE LA ÉPOCA ROMANA Y TARDOANTIGUA EN HISPANIA: DOCUMENTACIÓN Y ESTUDIO DE LA EPIGRAFÍA Y LA NUMISMÁTICA DE LOS BALNEARIOS Y LAS FUENTES MINEROMEDICINALES

Entidad financiadora: Fundación Séneca-Agencia de Ciencia y Tecnología de la Región de Murcia. Programa de Apoyo a la Investigación Científica y Técnica y a la Transferencia de conocimientos (ref. 15387-PHCS-10)

Duración desde: 2011 hasta: 2014

\section{PROYECTOS Y CONTRATOS CON EMPRESAS Y/O ADMINISTRACIONES}

1. Título: ESTUDIO DE LAS AGUAS TERMALES DEL MANANTIAL SONDEO "EL SALADILLO” TERMINO MUNICIPAL DE MAZARRON (MURCIA)

Tipo de contrato: (L.R.U., $\mathrm{Art}^{\mathrm{o}} 11$ )

Empresa/Administración financiadora: Mazarron Balneario Termal, S.L. (ref. 4151167-FGUCM-190/2000)

Duración desde: $2000 \quad$ hasta: 2001

2. Título: ESTUDIO SOBRE EL TRATAMIENTO TERMAL EN EL BALNEARIO DE PUENTE VIESGO (CANTABRIA)

Tipo de contrato: (L.R.U., Art $\left.^{\circ} 11\right)$

Empresa/Administración financiadora: Balneario de Puente Viesgo, S.A. (ref. FUE2292)

Duración desde: 2000 hasta: 2003

3. Título: ESTUDIO DE LAS AGUAS MINERALES DE LOS BAÑOS DE LA GUARRAPA, VALDASTILLA-EL TORNO (CACERES)

Tipo de contrato: (L.R.U., Art $^{\circ} 11$ )

Empresa/Administración financiadora: DIRVOS, S.L. (ref. 4151304 -FGUCM85/2001)

Duración desde: 2001 hasta: 2001

4. Título: ESTUDIO DE LAS AGUAS MINERALES DEL SONDEO "LA GARGANTA” (CREVILLENT-ALICANTE)

Tipo de contrato: (L.R.U., Art $^{\circ} 11$ )

Empresa/Administración financiadora: Ayuntamiento de Crevillente (ref. 4151435 FGUCM-313/2001)

Duración desde: 2001 hasta: 2001

5. Título: ESTUDIO DE LAS AGUAS MINEROMEDICINALES DE LOS BAÑOS DE ARIÑO (TERUEL)

Tipo de contrato: (L.O.U., Art $^{\circ} 83$ )

Empresa/Administración financiadora: Ayuntamiento de Ariño (ref. 4151417 FGUCM-106/2002)

Duración desde: 2002 hasta: 2002 
6. Título: MEJORA TECNOLOGICA DE UN PROCESO DE PRODUCCIÓN DE LODOS DESTINADOS A APLICACIONES BALNEOTERAPICAS

Tipo de contrato: (L.O.U., $\mathrm{Art}^{\circ} 83$ )

Empresa/Administración financiadora: Balneario El Raposo, S.L. (ref. 4151669 FGUCM-30/2003)

Duración desde: 2002

hasta: 2003

7. Título: ESTUDIO DE LAS AGUAS MINERALES NATURALES DESDE EL PUNTO DE VISTA NUTRICIONAL Y SANITARIO

Tipo de contrato: (L.O.U., Art $^{\circ} 83$ )

Empresa/Administración financiadora: Font Vella, S.A. (ref. 4150185 -FGUCM156/2003)

Duración desde: $2003 \quad$ hasta: 2004

8. Título: ESTUDIO DE LAS AGUAS MINERALES DEL SONDEO SALOBREÑA (SALOBREÑA-GRANADA)

Tipo de contrato: (L.O.U., Art $^{\circ} 83$ )

Empresa/Administración financiadora: AGMA, S.L. (ref. 4151704 -FGUCM267/2003)

Duración desde: $2003 \quad$ hasta: 2003

9. Título: ESTUDIO DEL AGUA DE FUENTE ALTA (VILAFLOR-SANTA CRUZ DE TENERIFE)

Tipo de contrato: (L.O.U., Art $^{\circ} 83$ )

Empresa/Administración financiadora: Aguas de Vilafor, S.A. (ref. 4130022 FGUCM-400/2003)

Duración desde: $2003 \quad$ hasta: 2003

10. Título: ESTUDIO DE LAS AGUAS MINERALES DEL SONDEO "LOS PASTOREROS” DEL CORTIJO DEL AIRE SITO EN SANTA FE (GRANADA)

Tipo de contrato: (L.O.U., Art $^{\circ} 83$ )

Empresa/Administración financiadora: FADESA (ref. 4150799 -FGUCM-292/2004)

Duración desde: 2004

hasta: 2004

11. Título: ESTUDIO DE LAS AGUAS MINERALES DE LOS BAÑOS DE MULA (MULA - MURCIA)

Tipo de contrato: (L.O.U., $\mathrm{Art}^{\circ}$ 83)

Empresa/Administración financiadora: Comunidad de Propietarios Baños de Mula (ref. 4151773 -FGUCM-374/2004)

Duración desde: $2004 \quad$ hasta: 2004

12. Título: ESTUDIO DE LAS AGUAS MINERALES DEL SONDEO CORTIJO DE LOS TRANCOS (ALMERÍA)

Tipo de contrato: (L.O.U., Art $^{\circ}$ 83)

Empresa/Administración financiadora: AGMA, S.L. (ref. 4150347 -FGUCM-27/2004)

Duración desde: 2004

hasta: 2004 
13. Título: ESTUDIO DE LAS AGUAS MINERALES DEL SONDEO No 26 DEL PARAJE ZARZALÓN EN CANENA (JAÉN)

Tipo de contrato: (L.O.U., $\mathrm{Art}^{\circ} 83$ )

Empresa/Administración financiadora: Balneario De San Andrés, S.L. (ref. 4151782 FGUCM-4/2005)

Duración desde: 2004

hasta: 2005

14. Título: ESTUDIO ANALÍTICO DE LAS AGUAS MINERALES NATURALES DE "VERI", "FUENTE LIVIANA" Y "FUENTE DEL MARQUESADO

Tipo de contrato: (L.O.U., Art $^{\circ} 83$ )

Empresa/Administración financiadora: Grupo Damm (ref. 4152039 -FGUCM-

Duración desde: 2004 414/2004)

15. Título: ESTUDIO DE LAS AGUAS MINERALES DEL SONDEO "PEÑA UMBRÍA”, SITO EN EL TÉRMINO MUNICIPAL DE REQUENA (VALENCIA)

Tipo de contrato: (L.O.U., Art $^{\circ} 83$ )

Empresa/Administración financiadora: Peña Umbría, S.L. (ref. 4151862 -FGUCM158/2005)

Duración desde: $2005 \quad$ hasta: 2005

16. Título: ESTUDIO DE LAS AGUAS MINERALES DEL SONDEO "SERRETA" DEL PARAJE "ELS JUNCAREJOS", SITO EN EL TÉRMINO MUNICIPAL DE FUENTE LA HIGUERA (VALENCIA)

Tipo de contrato: (L.O.U., Art $^{\circ}$ 83)

Empresa/Administración financiadora: Agua Mineral Font Teca, S.A. (ref. 4151875 FGUCM-185/2005)

Duración desde: 2005 hasta: 2005

17. Título: ESTUDIO DE LAS AGUAS MINERALES DEL BALNEARIO DE ARTÍES (LLEIDA)

Tipo de contrato: (L.O.U., Art $^{\circ} 83$ )

Empresa/Administración financiadora: Era-Luna, S.L. (ref. 4151883 -FGUCM186/2005)

Duración desde: $2005 \quad$ hasta: 2005

18. Título: ESTUDIO DE LAS AGUAS MINERALES DEL MANANTIAL "POZO SALADO”, SITO EN EL TÉRMINO MUNICIPAL DE CASAS BAJAS (VALENCIA) Tipo de contrato: (L.O.U., Art $^{\circ} 83$ )

Empresa/Administración financiadora: Ayuntamiento de Casas Bajas (Valencia) (ref.

Duración desde: 2005

4151801 -FGUCM-34/2005)

hasta: 2005 
19. Título: ESTUDIO DE LAS AGUAS MINERALES DEL SONDEO "FONT D’ABAIX-P-2”, SITO EN EL TÉRMINO MUNICIPAL DE ORPÍ (BARCELONA) Tipo de contrato: (L.O.U., Art $^{\circ} 83$ ) Empresa/Administración financiadora: Manantiales Homs, S.A. (ref. 4152156 FGUCM-80/2006)

Duración desde: 2006 hasta: 2006

20. Título: ESTUDIO DE LAS AGUAS MINERALES DEL MANANTIAL "FONT DE SA SENYORA (DEIÁ - MALLORCA)

Tipo de contrato: (L.O.U., $\mathrm{Art}^{\circ} 83$ )

Empresa/Administración financiadora: PROEMA, S.L. (ref. 4152037 -FGUCM29/2006)

Duración desde: $2006 \quad$ hasta: 2006

21. Título: ESTUDIO ANALÍTICO DE LAS AGUAS MINEROMEDICINALES DE CARABAÑA (MADRID)

Tipo de contrato: (L.O.U., Art $^{\circ} 83$ )

Empresa/Administración financiadora: CHAPLAN, S.A. (ref. 4152287 -FGUCM324/2006)

Duración desde: $2006 \quad$ hasta: 2007

22. Título: ESTUDIO DE LAS AGUAS MINERALES SITO EN EL TÉRMINO MUNICIPAL DE CARABAÑA (MADRID)

Tipo de contrato: (L.O.U., $\mathrm{Art}^{\mathrm{o}} \mathrm{83}$ )

Empresa/Administración financiadora: TROME, S.A.. (ref. 4152288 -FGUCM325/2006)

Duración desde: $2006 \quad$ hasta: 2007

23. Título: ESTUDIO DE LAS AGUAS MINERALES SITO EN EL TÉRMINO MUNICIPAL DE CARABAÑA (MADRID)

Tipo de contrato: (L.O.U., Art $^{\circ} 83$ )

Empresa/Administración financiadora: CHAPLAN, S.A. (ref. 4152289 -FGUCM326/2006)

Duración desde: 2006 hasta: 2007

24. Título: ESTUDIO DE LOS LIMOS MARINOS Y ANÁLISIS DE LAS AGUAS DE LA PLAYA DE LA CACHUCHA DE PUERTO REAL (CÁDIZ)

Tipo de contrato: (L.O.U., Art $^{\circ} 83$ )

Empresa/Administración financiadora: Mancomunidad de Municipios de la Bahía de Cádiz (ref. 4152261 -FGUCM-262/2006)

Duración desde: 2006

hasta: 2006 
25. Título: ESTUDIO DE LAS AGUAS MINERALES DEL SONDEO SANTA ANA PECHINA (ALMERÍA)

Tipo de contrato: (L.O.U., $\mathrm{Art}^{\circ} 83$ )

Empresa/Administración financiadora: Playa Calipso, S.A. (ref. 4152385 -FGUCM450/2006)

Duración desde: 2006 hasta: 2007

26. Título: ESTUDIO DE LOS FACTORES TALASOHÍDRICOS, LIMOS MARINOS Y ANÁLISIS DE LAS AGUAS DE LA PLAYA DE LA CACHUCHA DE PUERTO REAL (CÁDIZ) Y SU UTILIZACIÓN EN TURISMO DE SALUD

Tipo de contrato: (L.O.U., Art $^{\circ} 83$ )

Empresa/Administración financiadora: Mancomunidad de Municipios de la Bahía de Cádiz (ref. 4152261A -FGUCM-253/2007)

Duración desde: 2007

hasta: 2007

27. Título: ESTUDIO DE LAS AGUAS MINERALES DEL MANANTIAL "EL SALOBRAL”, SITO EN EL TÉRMINO MUNICIPAL DE VINUESA (SORIA)

Tipo de contrato: (L.O.U., Art $^{\circ}$ 83)

Empresa/Administración financiadora: Luis Alberto Carrión Matamoros (ref. 4152683 -FGUCM-411/2007)

Duración desde: 2007

hasta: 2008

28. Título: II VADEMÉCUM DE AGUAS MINEROMEDICIALES ESPAÑOLAS

Tipo de contrato: (L.O.U., $\mathrm{Art}^{\mathrm{o}} 83$ )

Empresa/Administración financiadora: Asociación Nacional de Balnearios - ANBAL (ref. 4130598 -FGUCM-410/2007)

Duración desde: 2007

hasta: 2009

29. Título: EFECTO DEL FANGO TERMAL DE COPAHUE PROCESADO Y RECONSTITUIDO CON AGUAS MINEROMEDICINALES DE DIFERENTES TERMAS ESPAÑOLAS, SOBRE AFECCIONES CUTÁNEAS

Tipo de contrato: (L.O.U., Art $^{\circ} 83$ )

Empresa/Administración financiadora: Fundación Pablo Cassará (ref. 4130582 FGUCM-387/2007)

Duración desde: 2007 hasta: 2009

30. Título: CATÁlOGO DE LAS MEMORIAS DE LAS AGUAS MINERO MEDICINALES ESPAÑOLAS (SIGLOS XIX Y XX) EXISTENTES EN LA BIBLIOTECA DE LA FACULTAD DE MEDICINA DE LA UNIVERSIDAD COMPLUTENSE DE MADRID

Tipo de contrato: (L.O.U., Art $^{\circ} 83$ )

Empresa/Administración financiadora: Asociación Nacional Empresas Agua Bebeda

Duración desde: 2008

Envasadas - ANEABE (ref. 4152778 -FGUCM-126/2008)

hasta: 2008 
31. Título: REALIZACIÓN DE ANALÍTICA Y ELABORACIÓN DEL INFORME SANITARIO-VINCULANTE PARA LA DECLARACIÓN DE MINEROMEDICINAL DE LAS AGUAS DEL SONDEO LA MALAHÁ

Tipo de contrato: (L.O.U., Art ${ }^{\circ} 83$ )

Empresa/Administración financiadora: PROMOVEGA-SIERRA ELVIRA (ref.

Duración desde: 2007 4152702 -FGUCM-448/2007)

hasta: 2008

32. Título: ESTUDIO ANALÍTICO DE LAS AGUAS MINERALES DE LA REGIÓN DEL NEUQUÉN - REPÚBLICA ARGENTINA

Tipo de contrato: (L.O.U., Art $^{\circ} 83$ )

Empresa/Administración financiadora: Ente Provincial de Termas del Neuquén EPROTEN (ref. 4130608 -FGUCM-127/2008)

Duración desde: 2008

hasta: 2009

33. Título: ESTUDIO DE LAS AGUAS MINERALES DEL POZO SITO EN LA CONFLUENCIA CALLE MENORCA CON LA AVENIDA DE FRANCIA, EN EL TÉRMINO MUNICIPAL DE VALENCIA (VALENCIA)

Tipo de contrato: (L.O.U., Art $^{\circ} 83$ )

Empresa/Administración financiadora: URBEM, S.A. (ref. 4153058 -FGUCM173/2008)

Duración desde: $2008 \quad$ hasta: 2008

34. Título: ESTUDIO DE LAS AGUAS MINERALES DEL MANANTIAL BELIENA, SITO EN EL TÉRMINO MUNICIPAL DE VILLENA (ALICANTE)

Tipo de contrato: (L.O.U., $\mathrm{Art}^{\circ} 83$ )

Empresa/Administración financiadora: Aguas Font Vella y Lanjarón, S.A. (ref. 4152974 -FGUCM-477/2008)

Duración desde: $2008 \quad$ hasta: 2009

35. Título: ESTUDIO DE CARACTERIZACIÓN TERMOFÍSICA DEL PELOIDE DEL MANANTIAL SALADO DE LANJARÓN Y SU APLICACIÓN TERAPÉUTICA

Tipo de contrato: (L.O.U., Art ${ }^{\circ} 83$ )

Empresa/Administración financiadora: Balneario de Lanjarón, S.A. (ref. 4153193 FGUCM-376/2009)

Duración desde: 2009

hasta: 2011

36. Título: ORGANIZACIÓN DE UN CONGRESO INTERNACIONAL DEDICADO A LOS PRODUCTOS DERIVADOS DE LAS AGUAS MINERALES

Tipo de contrato: (L.O.U., $\operatorname{Art}^{\circ} 83$ )

Empresa/Administración financiadora: Aguas Font Vella y Lanjarón, S.A. (ref. 4153317 -FGUCM-100/2010)

Duración desde: $2010 \quad$ hasta: 2010 
37. Título: DETERMINACIÓN DE PROPIEDADES TERAPÉUTICAS DE MEZCLAS Y PELOIDES PARA SU APLICACIÓN EN BALNEARIOS Y TALASOS

Tipo de contrato: (L.O.U., $\mathrm{Art}^{\circ} 83$ )

Empresa/Administración financiadora: Süd Chimie España, S.L., Balneario del Atlántico, S.L., Hervideros de Cofrentes, S.L., Hostelera Noroeste, S.A., Termas de Cuntis, S.L. y Baños y Salud, S.L. (ref. 4153338 -FGUCM-127/2010)

Duración desde: 2010 hasta: 2012

38. Título: ESTUDIO DE LAS AGUAS MINERALES DE LOS SONDEOS No 23 Y 31 DE ALHAMA, SITO EN EL TÉRMINO MUNICIPAL DE ALHAMA DE ALMERÍA (ALMERÍA)

Tipo de contrato: (L.O.U., $\mathrm{Art}^{\mathrm{o}} 83$ )

Empresa/Administración financiadora: Alhameña de Hostelería, S.L. (ref. 4153499 FGUCM-432/2010)

Duración desde: $2010 \quad$ hasta: 2011

39. Título: ESTUDIO DE LAS AGUAS MINERALES DEL SONDEO DENOMINADO “CIJUELA No 1”, SITO EN EL TÉRMINO MUNICIPAL DE CIJUELA (GRANADA) Tipo de contrato: (L.O.U., Art $^{\circ} 83$ )

Empresa/Administración financiadora: Proyectos y Servicios Integrales del Sur, S.L.

Duración desde: 2011 (ref. 4153648 -FGUCM-123/2011)

hasta: 2011

40. Título: ORGANIZACIÓN DE UN CONGRESO INTERNACIONAL DEDICADO A LAS AGUAS MINERALES

Tipo de contrato: (L.O.U., $\mathrm{Art}^{\circ} 83$ )

Empresa/Administración financiadora: Aguas Font Vella y Lanjarón, S.A. (ref. 4153646 -FGUCM-107/2011)

Duración desde: $2011 \quad$ hasta: 2012

41. Título: ESTUDIO DE LAS AGUAS MINERALES DEL SONDEO DENOMINADO "POZO SANTIAGO", SITO EN EL TÉRMINO MUNICIPAL DE VILLENA (ALICANTE)

Tipo de contrato: (L.O.U., Art ${ }^{\circ} 83$ )

Empresa/Administración financiadora: RODES, Ingeniería de Recursos naturales, S.L. (ref. 4153953 -FGUCM-374/2011)

Duración desde: 2011 hasta: 2012 


\section{PUBLICACIONES}

\section{Publicaciones en revistas científicas}

Nacionales

1. Concentración de fluoruros en las aguas minerales naturales envasadas en España y Portugal: relación con la prevención de la caries y la fluorosis dental. Odontopediatría Pediátrica. 2001; 9(2): 89-92.

ISSN 1113-5181

2. Acción terapéutica de las aguas del Balneario "El Paraíso" de Manzanera (Teruel)

Anales de la Real Academia de Farmacia. 2001; 67(E): 235-251

ISSN 00340618

3. Revisión de los conocimientos actuales sobre microelementos minerales $\mathrm{u}$ oligoelementos

Boletín de la Sociedad Española de Hidrología Médica. 2001; 16(2): 67-69

ISSN 0214-2813

4. Oligoelementos esenciales: biodisponibilidad y papel fisiológico

Boletín de la Sociedad Española de Hidrología Médica. 2001; 16(2): 71-82

ISSN 0214-2813

5. Hierro oligoelemento esencial

Boletín de la Sociedad Española de Hidrología Médica. 2001; 16(2): 83-90

6. Cobre oligoelemento esencial

Boletín de la Sociedad Española de Hidrología Médica. 2001; 16(2): 91-98

ISSN 0214-2813

7. Selenio oligoelemento esencial

Boletín de la Sociedad Española de Hidrología Médica. 2001; 16(2): 99-101

ISSN 0214-2813

8. Resumen sinóptico de los oligoelementos esenciales en humanos. Legislación y recomendaciones dietéticas

Boletín de la Sociedad Española de Hidrología Médica. 2001; 16(3): 127-134

ISSN 0214-2813 
9. Zinc oligoelemento esencial

Boletín de la Sociedad Española de Hidrología Médica. 2001; 16(3): 135-141 ISSN 0214-2813

10. Manganeso oligoelemento esencial

Boletín de la Sociedad Española de Hidrología Médica. 2001; 16(3): 143-146 ISSN 0214-2813

11. Acción terapéutica de las aguas del Balneario de "Alhama de Granada" Anales de la Real Academia de Farmacia. 2002; 68: 475-500 ISSN 00340618

12. Epidemiología de la legionelosis y consideraciones sobre su prevención en Balnearios

Boletín de la Sociedad Española de Hidrología Médica. 2002; 17(2): 67-89 ISSN 0214-2813

13. Resumen histórico farmacológico terapéutico de las aguas minerales de Firgas Canarias Médica y Quirúrgica. 2003; 1(1): 50-53.

ISSN 1696-6864

14. Informe acerca de las aguas minerales de los Baños de Ariño (Teruel) Revista de Andorra. 2003; 3: 150-155.

ISSN 1567-3469

15. Constancia diacrónica de las aguas minerales de Firgas (Islas Canarias) y usos terapéuticos

Nutrición clínica y dietética hospitalaria. 2003; 23(3): 15-23.

ISSN 0021-6057

16. Acción terapéutica de las aguas de los Balnearios de Jaraba Anales de la Real Academia de Farmacia. 2004; 70: 625-653 ISSN 00340618

17. Tratamiento crenoterápico de la sinusitis en la infancia Medicina Naturista. 2006; 9: 472-477.

ISSN 1576-3080

18. Estudio de los peloides de las termas de Copahué (Neuquén - Argentina): características y propiedades

Boletín de la Sociedad Española de Hidrología Médica. 2006; 21(1): 9-13

ISSN 0214-2813 
19. Presentación

Anales de Hidrología Médica. 2006; 1: 13

ISSN 1887-0813

20. Antecedentes históricos de la peloterapia

Anales de Hidrología Médica. 2006; 1: 17-42

ISSN 1887-0813

21. Propiedades físicas de los Peloides españoles Anales de Hidrología Médica. 2006; 1: 43-53 ISSN 1887-0813

22. Granulometría y textura de los Peloides españoles Anales de Hidrología Médica. 2006; 1: 79-96 ISSN 1887-0813

23. Curva de enfriamiento de los Peloides españoles - Propiedades térmicas Anales de Hidrología Médica. 2006; 1: 97-110 ISSN $1887-0813$

24. Estudio analítico de las aguas minerales empleadas en la maduración de los Peloides españoles

Anales de Hidrología Médica. 2006; 1: 119-133

ISSN $1887-0813$

25. Reseña: La Presse Thermale et Climatique (ed.), Florílège termal. Les 150 ans de la Société

Anales de Hidrología Médica. 2007; 2: 169-171

ISSN 1887-0813

26. Reseña: Aguas Envasadas y Balnearios

Anales de Hidrología Médica. 2007; 2: 171-173

ISSN 1887-0813

27. Reseña: Establecimientos balnearios: historia, literatura y medicina Anales de Hidrología Médica. 2007; 2: 173-176 ISSN 1887-0813

28. Reseña: Historia de la Sociedad Española de Hidrología Médica. Siglo XIX Anales de Hidrología Médica. 2007; 2: 177-178

ISSN 1887-0813 
29. Reseña: El libro blanco de la hidratación Anales de Hidrología Médica. 2007; 2: 178-180 ISSN 1887-0813

30. Reseña: Técnicas y Tecnología en Hidrología Médica e Hidroterapia Anales de Hidrología Médica. 2007; 2: 180-182 ISSN 1887-0813

31. Terapias complementarias olvidadas en la fibromialgia Medicina Clínica (Barcelona). 2009; 133(15): 605-606 ISSN 0025-7753. doi:10.1016/j.medcli.2008.11.028

32. ¿Es igual el agua del grifo que el agua envasada? No, sin duda, no Medicina Clínica (Barcelona). 2010; 134(1): 40-42 ISSN 0025-7753. doi:10.1016/j.medcli.2009.01.011

33. La reeducación funcional en los Establecimientos Balnearios españoles Anales de Hidrología Médica. 2010; 3: 45-60 ISSN 1887-0813

34. Evaluación de los cambios en la piel tras la aplicación de una emulsión facial con sales de la capuchina mediante métodos de bioingeniería cutánea Anales de Hidrología Médica. 2010; 3: 61-77 ISSN 1887-0813

35. Historia de los Baños de Ariño a través de sus análisis Anales de Hidrología Médica. 2010; 3: 131-158 ISSN 1887-0813

36. Propuesta de programa de la especialidad de "Hidrologia Médica" Anales de Hidrología Médica. 2010; 3: 159-208 ISSN $1887-0813$

37. Reseña: Viajes de Agua. Las aguas en el Pirineo aragonés a través de sus viajeros

Anales de Hidrología Médica. 2010; 3: 209-210 ISSN 1887-0813

38. Reseña: Estética Hidrotermal Anales de Hidrología Médica. 2010; 3: 210-211 ISSN 1887-0813 
39. Reseña: Mineralogía Aplicada

Anales de Hidrología Médica. 2010; 3: 212

ISSN 1887-0813

40. Reseña: Clima y medicina. Los orígenes del turismo en Canarias. Santa Cruz de Tenerife

Anales de Hidrología Médica. 2010; 3: 213-214

ISSN 1887-0813

41. Reseña: Análisis químico general y aplicado a suelos y aguas

Anales de Hidrología Médica. 2010; 3: 214-215

ISSN 1887-0813

42. Reseña: Investigación en el ámbito iberoamericano sobre peloides termales Anales de Hidrología Médica. 2010; 3: 215-217 ISSN 1887-0813

43. Reseña: Curso de Termalismo: Peloides termales Anales de Hidrología Médica. 2010; 3: 218-219 ISSN $1887-0813$

44. Reseña: La terapia termale inalatoria: attualita' e prospettive future Anales de Hidrología Médica. 2010; 3: 219-220 ISSN $1887-0813$

45. Reseña: Memorias de las aguas mineromedicinales españolas (Siglo XIX-XX) Anales de Hidrología Médica. 2010; 3: 221 ISSN $1887-0813$

46. Reseña: El termalismo argentino Anales de Hidrología Médica. 2010; 3: 222-223 ISSN 1887-0813

47. Reseña: Termatalia. Sesión Científica sobre Termalismo de la Real Academia de Medicina y Cirugía de Galicia Anales de Hidrología Médica. 2010; 3: 223-224 ISSN 1887-0813

48. Reseña: Técnicas hidrotermales y estética del bienestar Anales de Hidrología Médica. 2010; 3: 225-226 ISSN 1887-0813 
49. Reseña: Galicia, Terma bimilenaria Anales de Hidrología Médica. 2010; 3: 226-227 ISSN 1887-0813

50. Reseña: Termas de Copahue. CPH"Lugar de Baños" Anales de Hidrología Médica. 2010; 3: 227-228 ISSN 1887-0813

51. Reseña: Guía de las Aguas de Castilla y León. Aguas Minerales Naturales y Termales

Anales de Hidrología Médica. 2010; 3: 228-229 ISSN 1887-0813

52. Reseña: Glossar Kur, Heilbad, Rehabilitation Anales de Hidrología Médica. 2010; 3: 229 ISSN 1887-0813

53. Reseña: O Desenho das Termas. História da Arquitectura Termal Portuguesa Anales de Hidrología Médica. 2010; 3: 230 ISSN $1887-0813$

54. Reseña: Termalismo e Águas Engarrafadas. Perspectiva Pluridisciplinar Anales de Hidrología Médica. 2010; 3: 231 ISSN $1887-0813$

55. Reseña: El agua mineral natural en la infancia Anales de Hidrología Médica. 2010; 3: 232-233 ISSN 1887-0813

56. Reseña: Vademecum II de aguas mineromedicinales españolas Anales de Hidrología Médica. 2011; 4: 145-146 ISSN 1887-0813

57. Reseña: Análisis del agua Anales de Hidrología Médica. 2011; 4: 146-147 ISSN 1887-0813

58. Reseña: Agua $\mathrm{H}_{2} \mathrm{O}$ la fórmula de la salud Anales de Hidrología Médica. 2011; 4: 147-148 ISSN 1887-0813 
59. Reseña: L'Etablissement Thermal de Saujon Anales de Hidrología Médica. 2011; 4: 148-149 ISSN 1887-0813

60. Papel de las aguas minerales ricas en calcio en la osteoporosis Medicina Clínica (Barcelona). 2011; 137(13): 619-620 ISSN 0025-7753. doi:10.1016/,.medcli.2011.04.011

61. Reseña: Comprehensive Aquatic Therapy Anales de Hidrología Médica. 2012; 5(2): 183-184 ISSN 1887-0813

62. Reseña: Cien años de análisis de las aguas mineromedicinales Anales de Hidrología Médica. 2012; 5(2): 184-185 ISSN 1887-0813

63. Reseña: Standard Methods for examination of water and wastewater. Anales de Hidrología Médica. 2012; 5(2): 185-186 ISSN 1887-0813

64. Reseña: Viajes de Agua II. Balnearios y manantiales de Granada a través de viajeros e hidrólogos

Anales de Hidrología Médica. 2012; 5(2): 186-188 ISSN 1887-0813

65. Reseña: Medical Hydrology and Balneology: Environmental Aspect Anales de Hidrología Médica. 2012; 5(2): 188-189 ISSN 1887-0813

66. Reseña: Procedimientos generales de fisioterapia. Práctica basada en la evidencia Anales de Hidrología Médica. 2012; 5(2): 189-190 ISSN 1887-0813

Internacionales

1. L'Hydrologie Médicale dans l'Espagne de "La Restauration": 1874-1902 La Presse Thermale et Climatique. 2007; 144: 151-163 ISSN 0032-7875 
2. L'enseignement de l'hydrologie dan l'Université Complutense de Madrid (Espagne) - Trente années de l'Ecole Professionnelle d'Hydrologie Médicale et d'Hydrothérapie

La Presse Thermale et Climatique. 2007; 144: 167-176 ISSN 0032-7875

3. Natural radioactivity of spring water used as spas in Spain Journal of Radioanalytical and Nuclear Chemistry. 2008; 277(3): 625-630 ISSN 0236-5731. doi:10.1007/s10967-007-7158-3

4. Mobility of elements in interaction between artificial sweat and peloids used in Spanish spas

Applied Clay Science. 2010; 48(3): 506-515

ISSN 0169-1317. doi:10.1016/j.clay.2010.02.016

5. Critical analysis of the Journal "Voprosy kurortologii fizioterpii i lechbenoi fizicheskoi kultury" by means of the Medical Hydrology articles published in the last 5 years

La Presse Thermale et Climatique. 2010; 147(2): 81-91

ISSN 0032-7875

6. Is thalassotherapy simply a type of climatotherapy?

International Journal of Biometeorology. 2011; 55(2): 107-108

ISSN 0020-7128. doi:10.1007/s00484-010-0382-5

7. Nicotine traces detected in bottled mineral water

Science of the Total Environment. 2012; 424: 356-7

ISSN 0048-9697. doi: 10.1016/j.scitotenv.2012.02.052

8. Survival human pathogenic bacteria in different types of natural mineral water Journal of Water and Health. 2012; 10(3): 400-405

ISSN 1477-8920. doi: 10.2166/wh.2012.009

9. ISMH Lanjarón - 20/23 Juin 2012

La Presse Thermale et Climatique. 2012; 149:113-116

ISSN 0032-7875 


\section{Libros}

1. Vademécum de aguas mineromedicinales españolas Madrid: ISCIII. 2003, 310 pp.

ISBN 84-95463-19-9

2. Vademécum of spanish mineral-medicinal waters Madrid: ISCIII. 2003, 304 pp. ISBN 84-95463-19-9

3. Historia de La Sociedad Española de Hidrología Médica. Siglo XIX Colección de Monografías Balnea $n^{\circ}$ 2. Madrid: Complutense. 2006, 274 pp. ISBN 978-84-669-2981-3

4. Viajes de Agua. Las aguas en el Pirineo aragonés a través de sus viajeros Jaca: Pirineum Ed. 2007, 197 pp. ISBN: 978-84-935061-3-1

5. Técnicas hidrotermales y estética del bienestar Madrid: Paraninfo. 2009, 333 pp.

ISBN 978-84-9732-679-7

6. Vademécum II de Aguas Mineromedicinales Españolas Madrid: Complutense. 2010, 365 pp. ISBN 978-84-7491-998-1

7. Cien años de análisis de las aguas mineromedicinales Colección de Monografías Balnea $n^{\circ}$ 5. Madrid: Complutense. 2012, 361 pp. ISBN 978-84-669-3474-9

8. Viajes de Agua II. Balnearios y manantiales de Granada a través de viajeros e hidrólogos

Madrid: Solprint. 2012, 333 pp.

ISBN 978-84-615-9269-2

9. Cien años de la Cátedra de Hidrología Médica

Colección de Monografías Balnea $n^{\circ}$ 7. Madrid: Complutense. 2012, 308 pp. ISBN 978-84-669-3474-9 
Edición y coordinación de Libros

1. Establecimientos Balnearios: Historia, Literatura y Medicina Colección de Monografías Balnea $n^{\circ}$ 1. Madrid: Complutense. 2006, 186 pp. ISBN 84-669-2879-0

2. Libro de resúmenes del II Congreso Iberoamericano de Peloides Madrid: CERSA. 2010, 120 pp. ISBN 978-84-614-2315-6

3. Medical Hydrology and Balneology: Environmental Aspect Colección de Monografías Balnea $n^{\circ}$ 6. Madrid: Complutense. 2012, 465 pp. ISBN 978-84-669-3482-4

\section{Colaboración}

1. Diccionario de términos médicos / Real Academia Nacional de Medicina Madrid: Médica Panamericana. 2012, XXXIV-1731 pp.

ISBN 978-84-9835-183-5

\section{Capítulos de Libros}

1. Hidrogeología en Técnicas hidrotermales aplicadas a Estética Integral Madrid: Videocinco. 2000, 36-44 ISBN 84-87190-65-0

2. Aplicaciones generales sin presión. Baños con aditivos en Técnicas hidrotermales aplicadas a Estética Integral

Madrid: Videocinco. 2000, 72-80

ISBN 84-87190-65-0

3. Termoterapia: Sauna y Baños de vapor en Técnicas hidrotermales aplicadas a Estética Integral

Madrid: Videocinco. 2000, 102-112

ISBN 84-87190-65-0

4. Talasoterapia en Técnicas hidrotermales aplicadas a Estética Integral Madrid: Videocinco. 2000, 151-163

ISBN 84-87190-65-0 
5. Presentación en Establecimientos Balnearios: Historia, Literatura y Medicina

Colección de Monografías Balnea $n^{\circ}$ 1. Madrid: Complutense. 2006, 9-10 ISBN 84-669-2879-0

6. Balnearios y manantiales del Pirineo Aragonés a través de los viajeros en Establecimientos Balnearios: Historia, Literatura y Medicina Colección de Monografías Balnea $n^{\circ}$ 1. Madrid: Complutense. 2006, 111-125 ISBN 84-669-2879-0

7. La figura del Médico-Director en el balneario de Lanjarón: siglo XIX en Establecimientos Balnearios: Historia, Literatura y Medicina

Colección de Monografías Balnea ${ }^{\circ} 1$. Madrid: Complutense. 2006, 127-146 ISBN 84-669-2879-0

8. Importancia del catálogo para el estudio de los antecedentes históricos de las aguas mineromedicinales y minerales naturales españolas en Memorias de las aguas mineromedicinales españolas. (Siglos XIX y XX)

Colección de Monografías Balnea $n^{o}$ 3. Madrid: Complutense. 2008, XVIXXIV

ISBN 978-84-669-3061-1

9. Balneoterapia: el remedio del mundo antiguo en Medicamentos, Placebos y Fraudes

Alcalá: Ed. Formación. 2008, 227-238

ISBN 978-84-96804-61-6

10. Prólogo en El termalismo argentino

Colección de Monografías Balnea ${ }^{\circ}$ 4. Madrid: Complutense. 2008, 11-12

ISBN 978-84-669-2981-3

11. Importancia de la medicina termal en EI termalismo argentino

Colección de Monografías Balnea $n^{\circ}$ 4. Madrid: Complutense. 2008, 35-50

ISBN 978-84-669-2981-3

12. Análisis de las aguas minerales de la provincia de Entre ríos, Argentina en El termalismo argentino

Colección de Monografías Balnea ${ }^{\circ}$ 4. Madrid: Complutense. 2008, 55-84

ISBN 978-84-669-2981-3 
13. Los peloides españoles: en la Cátedra de Hidrología Médica en Contribuciones científicas en memoria del Profesor Jesús Soto Torres

Santander: Universidad Cantabria. 2008, 97-110

ISBN 978-84-8102-522-4

14. Una reflexión dirigida a nuestros lectores en El agua mineral natural en la infancia

Madrid: ANEABE. 2009, 7-8

ISBN 978-84-92523-73-3

15. Las aguas minerales naturales en $\mathbf{E l}$ agua mineral natural en la infancia Madrid: ANEABE. 2009, 13-33

ISBN 978-84-92523-73-3

16. Prólogo en Termas de Copahue CPH Lugar de Baños

Neuquén: Ed. Patagónica. 2009, 7-10

ISBN 978-987-05-9332-4

17. Prólogo en Caminemos por las Termas del Neuquen

Bariloche: Editorial Caleuche. 2012, 9-10

ISBN 978-987-1373-28-4

18. Prólogo en Teror, la Fuente Agria y el histórico Balneario

Teror: Ed. IMCA. 2012, 11-12

ISBN 978-987-12011-58-7

\section{Publicaciones en Congresos y reuniones científicas}

Nacionales

1. Aguas envasadas de Lanjarón: evolución a lo largo del tiempo a través de sus etiquetas

Boletín de la Sociedad Española de Hidrología Médica. 2001; 16(1): 30

ISSN 0214-2813

Congreso Nacional de la Sociedad Española de Hidrología Médica 2000.

Archena. 01-02/12/2000

2. Alteraciones de los oligoelementos esenciales en humanos, legislación y recomendaciones dietéticas

Boletín de la Sociedad Española de Hidrología Médica. 2001; 16(1): 30 ISSN 0214-2813

Congreso Nacional de la Sociedad Española de Hidrología Médica 2000.

Archena. 01-02/12/2000 
3. Análisis fisicoquímico del agua Fita-Santa Fe: comparación de análisis anteriores

Boletín de la Sociedad Española de Hidrología Médica. 2001; 16(1): 30-31 ISSN 0214-2813

Congreso Nacional de la Sociedad Española de Hidrología Médica 2000.

Archena. 01-02/12/2000

4. Baños de Montemayor. Rehabilitación de un Balneario

Boletín de la Sociedad Española de Hidrología Médica. 2001; 16(1): 31-32

ISSN 0214-2813

Congreso Nacional de la Sociedad Española de Hidrología Médica 2000.

Archena. 01-02/12/2000

5. La estética termal en el Balneario de Lanjarón: revitalizador capuchina facial

Boletín de la Sociedad Española de Hidrología Médica. 2001; 16(1): 34-35

ISSN 0214-2813

Congreso Nacional de la Sociedad Española de Hidrología Médica 2000.

Archena. 01-02/12/2000

6. Estudio de la curva de temperatura de peloides artificiales de origen inorgánico

Boletín de la Sociedad Española de Hidrología Médica. 2001; 16(1): 35

ISSN 0214-2813

Congreso Nacional de la Sociedad Española de Hidrología Médica 2000.

Archena. 01-02/12/2000

7. Efectos de la ingesta de aguas minerales naturales Lanjarón-San Vicente sobre la morbilidad de pacientes hemodializados

Boletín de la Sociedad Española de Hidrología Médica. 2001; 16(1): 35

ISSN 0214-2813

Congreso Nacional de la Sociedad Española de Hidrología Médica 2000.

Archena. 01-02/12/2000

8. Gonartrosis y Termalismo Social en el Balneario de Lanjarón

Boletín de la Sociedad Española de Hidrología Médica. 2001; 16(1): 35-36

ISSN 0214-2813

Congreso Nacional de la Sociedad Española de Hidrología Médica 2000.

Archena. 01-02/12/2000

9. Oligoelementos: conceptos y generalidades

Boletín de la Sociedad Española de Hidrología Médica. 2001; 16(1): 36-37

ISSN 0214-2813

Congreso Nacional de la Sociedad Española de Hidrología Médica 2000.

Archena. 01-02/12/2000 
10. Oligoelementos esenciales: biodisponibilidad y papel fisiológico Boletín de la Sociedad Española de Hidrología Médica. 2001; 16(1): 37 ISSN 0214-2813

Congreso Nacional de la Sociedad Española de Hidrología Médica 2000. Archena. 01-02/12/2000

11. Los peloides del balneario de Archena: estudio químico-físico, de microscopía electrónica analítica y barrido

Boletín de la Sociedad Española de Hidrología Médica. 2001; 16(1): 37 ISSN 0214-2813

Congreso Nacional de la Sociedad Española de Hidrología Médica 2000. Archena. 01-02/12/2000

12. Perfil sociodemográfico del programa de Balneoterapia de la Junta de Extremadura en Montemayor

Boletín de la Sociedad Española de Hidrología Médica. 2001; 16(1): 37-38 ISSN 0214-2813

Congreso Nacional de la Sociedad Española de Hidrología Médica 2000. Archena. 01-02/12/2000

13. Perfil socio-demográfico del programa de la población balnearia de Lanjarón (Granada) beneficiaria del programa de Termalismo Social

Boletín de la Sociedad Española de Hidrología Médica. 2001; 16(1): 38-38 ISSN 0214-2813

Congreso Nacional de la Sociedad Española de Hidrología Médica 2000. Archena. 01-02/12/2000

14. Repercusión en el gasto farmacéutico por la utilización del agua mineromedicinal de Carabaña en una residencia de ancianos

Boletín de la Sociedad Española de Hidrología Médica. 2001; 16(1): 39-39 ISSN 0214-2813

Congreso Nacional de la Sociedad Española de Hidrología Médica 2000. Archena. 01-02/12/2000

15. Resultados de la valoración en el análisis sistemático de la orina de pacientes sometidos a cura hidropónica en el Balneario de Cervantes Boletín de la Sociedad Española de Hidrología Médica. 2001; 16(1): 39-40 ISSN 0214-2813

Congreso Nacional de la Sociedad Española de Hidrología Médica 2000. Archena. 01-02/12/2000 
16. Selenio. Funciones. Déficit y Toxicidad. Patología asociada Boletín de la Sociedad Española de Hidrología Médica. 2001; 16(1): 40 ISSN 0214-2813

Congreso Nacional de la Sociedad Española de Hidrología Médica 2000. Archena. 01-02/12/2000

17. Zinc, Cobre y Manganeso. Funciones. Déficit y Toxicidad. Patología asociada Boletín de la Sociedad Española de Hidrología Médica. 2001; 16(1): 40 ISSN 0214-2813

Congreso Nacional de la Sociedad Española de Hidrología Médica 2000. Archena. 01-02/12/2000

18. Tendencias actuales de la Cura Balnearia

Revista de Andorra. 2003; 3: 78-83.

ISSN 1567-3469

Jornadas sobre "Las aguas minero-medicinales del manantial de los Baños" Ariño (Teruel) 26-27/04/2002

19. Historia de los baños de Ariño a través de sus análisis Revista de Andorra. 2003; 3: 118-143.

ISSN 1567-3469

Jornadas sobre "Las aguas minero-medicinales del manantial de los Baños" Ariño (Teruel) 26-27/04/2002

20. Pharmacological activity of mineral waters of Firgas (Canary Islands)

Methods and findings in experimental and clinical pharmacology. 2002; 24(Suppl.): 128

ISSN 0379-0355

XXIV Congreso de la Sociedad Española de Farmacología Médica 2002.

Toledo. 22-25/09/2002

21. Actividad cardiovascular de las aguas minerales de Firgas (Islas Canarias) Boletín de la Sociedad Española de Hidrología Médica. 2003; 18(1): 27-27 ISSN 0214-2813

Congreso Nacional de la Sociedad Española de Hidrología Médica 2002. Puente Viesgo. 22-23/11/2002

22. Estudio del azufre reducido de las aguas mineromedicinales españolas Boletín de la Sociedad Española de Hidrología Médica. 2003; 18(1): 30-30 ISSN 0214-2813

Congreso Nacional de la Sociedad Española de Hidrología Médica 2002. Puente Viesgo. 22-23/11/2002 
23. Las aguas mineromedicinales de Lanjarón-Capuchina en afecciones dermatológicas

Boletín de la Sociedad Española de Hidrología Médica. 2003; 18(1): 30-30 ISSN 0214-2813

Congreso Nacional de la Sociedad Española de Hidrología Médica 2002.

Puente Viesgo. 22-23/11/2002

24. El Olimpo y el Mar

Boletín de la Sociedad Española de Hidrología Médica. 2003; 18(2): 67-76

ISSN 0214-2813

Sesión Científica de la Sociedad Española de Hidrología Médica.

Madrid. 12/06/2003

25. Gastrointestinal effects of mineral waters of Firgas (Canary Islands).

Methods and findings in experimental and clinical pharmacology. 2003;

25(Suppl.): 159

ISSN 0379-0355

XXV Congreso de la Sociedad Española de Farmacología 2003.

Cádiz. 08-11/10/2003

26. Neurological and toxicological screening of mineral waters of Firgas. The Canary Islands.

Methods and findings in experimental and clinical pharmacology. 2004; 26(Suppl.): 122

ISSN 0379-0355

XXVI Congreso de la Sociedad Española de Farmacología 2004.

Salamanca. 26-29/09/2004

27. Apuntes para la Historia reciente del Termalismo extremeño

Boletín de la Sociedad Española de Hidrología Médica. 2005; 20(1): 43-47

ISSN 0214-2813

Congreso Nacional de la Sociedad Española de Hidrología Médica 2004.

Alange. 10-12/12/2004

28. Perfil sanitario y crenoterápico de los termalistas del Balneario de Baños de Montemayor durante la temporada 2004

Boletín de la Sociedad Española de Hidrología Médica. 2005; 20(1): 51

ISSN 0214-2813

Congreso Nacional de la Sociedad Española de Hidrología Médica 2004.

Alange. 10-12/12/2004 
29. Relación entre la composición de un peloide y su comportamiento térmico Boletín de la Sociedad Española de Hidrología Médica. 2005; 20(1): 52 ISSN 0214-2813

Congreso Nacional de la Sociedad Española de Hidrología Médica 2004. Alange. 10-12/12/2004

30. Curas hidrotermales en ginecología

Boletín de la Sociedad Española de Hidrología Médica. 2005; 20(2): 23-25

ISSN 0214-2813

Congreso Nacional de la Sociedad Española de Hidrología Médica 2004.

Alange. 10-12/12/2004

31. Los peloides del balneario de Caldes de Boí: estudio químico-físico, de microscopía electrónica analítica y barrido

Boletín de la Sociedad Española de Hidrología Médica. 2005; 20(2): 43-47

ISSN 0214-2813

Congreso Nacional de la Sociedad Española de Hidrología Médica 2004.

Alange. 10-12/12/2004

32. Situación de la peloidoterapia en Europa

Boletín de la Sociedad Española de Hidrología Médica. 2005; 20(2): 48-50

ISSN 0214-2813

Congreso Nacional de la Sociedad Española de Hidrología Médica 2004.

Alange. 10-12/12/2004

33. Caracterización Física y Físico-química de Peloides Españoles. Estudio de su Variabilidad

Macla. 2010; 13: 61-62

ISSN $1885-7264$

XXX Reunión de la Sociedad Española de Mineralogía SEM 2010.

Madrid. 13-16/09/2010

34. Estudio de la textura del peloide marino del centro Thalasia (Murcia)

Boletín de la Sociedad Española de Hidrología Médica. 2010; 25(2): 76

ISSN 0214-2813

Termatalia 2009 - Congreso Nacional de Hidrología Médica.

Ourense. 16-17/10/2009

35. Estudio de los peloides del Mar Menor (Murcia): características y propiedades Boletín de la Sociedad Española de Hidrología Médica. 2010; 25(2): 76 ISSN 0214-2813

Termatalia 2009 - Congreso Nacional de Hidrología Médica.

Ourense. 16-17/10/2009 
Internacionales

1. Balneotherapy at "Puente Viesgo's Spa" en Health Resort Medicine ind 2nd Millennium

Friedland: ISMH Verlag. 2004, 143-144

ISBN 3-934043-05-4

34 World Congress of the Internacional Society of Medical Hydrology and Climatology.

Budapest-Hévíz (Hungría). 14-19/10/2002

2. How does the pharmaceutical expenses affect by tht use of Carabana's mineral water in geriatric center en Health Resort Medicine ind 2nd Millennium Friedland: ISMH Verlag. 2004, 209

ISBN 3-934043-05-4

34 World Congress of the Internacional Society of Medical Hydrology and Climatology.

Budapest-Hévíz (Hungría). 14-19/10/2002

3. Effect of Lanjarón-San Vicente mineral water ingested, on morbility of hemodialized patients en Health Resort Medicine ind 2nd Millennium

Friedland: ISMH Verlag. 2004, 217

ISBN 3-934043-05-4

34 World Congress of the Internacional Society of Medical Hydrology and Climatology.

Budapest-Hévíz (Hungría). 14-19/10/2002

4. El agua en bebida, propiedades en Libro de Actas Termatalia 2003

Ourense: Expourense. 2003, 151

ISBN 84-609-6719-0

Termatalia 2003 - Jornadas Termatalia 2003.

Ourense. 31-02/10-11/2003

5. La Hidrología Médica en los Establecimientos Balnearios en Aguas Envasadas y Balnearios

Madrid: Universidad Politécnica. 2006, 171-180

ISBN 84-89683-06-9

I Foro ibérico sobre aguas envasadas y balnearios. ETSIM Madrid

Madrid. 15-16/03/2005 
6. Natural Mineral spanish waters as source of calcium and magnesium en Abstracts of the 15th European Congress of ESPRM

Madrid: SERMEF. 2006, 406

ISBN 84-689-8644-5

15th European Congress of Physical and Rehabilitation Medicine

Madrid. 16-20/05/2006

7. Functional Reeducation in spanish Spa en Abstracts of the 15th European Congress of ESPRM

Madrid: SERMEF. 2006, 587

ISBN 84-689-8644-5

15th European Congress of Physical and Rehabilitation Medicine

Madrid. 16-20/05/2006

8. Antecedentes historicos de la utilización de los peloides y situación actual en Investigaciones en el ámbito Iberoamericano sobre peloides termales

Vigo: Universidad de Vigo. 2008, 3-27

ISBN 978-84-8158-385-4

I Congreso Iberoamericano de Peloides.

Baiona. 04-07/11/2007

9. Textura y granulometría de los peloides en Investigaciones en el ámbito Iberoamericano sobre peloides termales

Vigo: Universidad de Vigo. 2008, 115-128

ISBN 978-84-8158-385-4

I Congreso Iberoamericano de Peloides.

Baiona. 04-07/11/2007

10. Curva de enfriamiento de peloides artificiales en Investigaciones en el ámbito Iberoamericano sobre peloides termales

Vigo: Universidad de Vigo. 2008, 237-242

ISBN 978-84-8158-385-4

I Congreso Iberoamericano de Peloides.

Baiona. 04-07/11/2007

11. Los peloides terapéuticos: experiencia de la Cátedra de Hidrología Médica en Sesión Científica sobre Termalismo

Ourense: Xunta de Galicia. 2009, 191-221

ISBN 978-84-612-9621-7

Termatalia 2008 - III Encuentro Internacional sobre Agua y Termalismo.

Ourense. 02/10/2008 
12. Radon and Radioactivity in Spain Spas of Different Geological Formations Arab Journal of Nuclear Sciences and Applications. 2009; 42(2): 349-358 ISSN 1110-0451

IX Radiation Physics \& Protection Conference.

El Cairo (Egipto). 15-19/11/2008

13. Estado de las aguas mineromedicinales en España

Boletín de la Sociedad Española de Hidrología Médica. 2010; 25(1): 21-23 ISSN 0214-2813

Termatalia 2009 - IV Encuentro Internacional sobre Agua y Termalismo. Ourense. 15/10/2009

14. Composición Química de las Aguas y Aspectos Sanitarios en Termalismo e Aguas Engarrafadas. Perspectiva Pluridisciplinar

Ponta Delgada: INOVA. 2009, 59-67

ISBN 978-989-95770-1-5

Encontro Internacional de Termalismo y Turismo Termal \& III Fórum Ibérico de Aguas Engarrafadas e Termalismo.

Furnas (Açores - Portugal). 02-06/11/2009

15. Medical hydrology teaching adapted to European higher education area

La Presse Thermale et Climatique. 2010; 147(1): 33-35

ISSN 0032-7875

37 World Congress of the Internacional Society of Medical Hydrology and Climatology.

Paris (Francia). 23-26/06/2010

16. Bottled natural mineral water and health

La Presse Thermale et Climatique. 2010; 147(1): 108-109

ISSN 0032-7875

37 World Congress of the Internacional Society of Medical Hydrology and Climatology.

Paris (Francia). 23-26/06/2010

17. Thermal treatment for elderly in a Spanish and French balneary

La Presse Thermale et Climatique. 2010; 147(1): 143-144

ISSN 0032-7875

37 World Congress of the Internacional Society of Medical Hydrology and Climatology.

Paris (Francia). 23-26/06/2010 
18. Skin response to osmotic cosmetics elaborated with mud made from chlorided ferruginous mineral water

La Presse Thermale et Climatique. 2010; 147(1): 153-154

ISSN 0032-7875

37 World Congress of the Internacional Society of Medical Hydrology and Climatology.

Paris (Francia). 23-26/06/2010

19. Socio-demographical characteristics of patients attending the Copahue hot springs (Neuquen-Argentine), Preliminary study

La Presse Thermale et Climatique. 2010; 147(1): 169-170

ISSN 0032-7875

37 World Congress of the Internacional Society of Medical Hydrology and Climatology.

Paris (Francia). 23-26/06/2010

20. Effectiveness of aquatic therapy in the treatment of fibromyalgia syndrome La Presse Thermale et Climatique. 2010; 147(1): 178-179 ISSN 0032-7875

37 World Congress of the Internacional Society of Medical Hydrology and Climatology.

Paris (Francia). 23-26/06/2010

21. Balneology (chlorided-ferruginous mineral water) in knee osteoarthritis treatment

La Presse Thermale et Climatique. 2010; 147(1): 181-182 ISSN 0032-7875

37 World Congress of the Internacional Society of Medical Hydrology and Climatology.

Paris (Francia). 23-26/06/2010

22. Evaluation of thalasotherapy in relation to the treatment of fibromialgia in comparison to the physical medicine techniques. Determination of the effectiveness and therapeutic patterns of application

La Presse Thermale et Climatique. 2010; 147(1): 183-184

ISSN 0032-7875

37 World Congress of the Internacional Society of Medical Hydrology and Climatology.

Paris (Francia). 23-26/06/2010 
23. Aquatic therapy in osteoporosis: a systematic review

La Presse Thermale et Climatique. 2010; 147(1): 186-187 ISSN 0032-7875

37 World Congress of the Internacional Society of Medical Hydrology and Climatology.

Paris (Francia). 23-26/06/2010

24. Study of the characteristics and properties of Thalasia's (Murcia) salt water peloid

La Presse Thermale et Climatique. 2010; 147(1): 188-189

ISSN 0032-7875

37 World Congress of the Internacional Society of Medical Hydrology and Climatology.

Paris (Francia). 23-26/06/2010

25. Estudio de las aguas mineromedicinales del Balneario de Lanjarón y su idoneidad para la maduración de peloides en Libro de resúmenes del II Congreso Iberoamericano de Peloides

Madrid: CERSA. 2010, 23-24

ISBN 978-84-614-2315-6

Lanjarón. 14-16/07/2010

26. Estudio analítico de las aguas de maduración de los peloides y sedimentos de las termas de Copahue (Neuquén - Argentina) en Libro de resúmenes del II Congreso Iberoamericano de Peloides

Madrid: CERSA. 2010, 27-28

ISBN 978-84-614-2315-6

Lanjarón. 14-16/07/2010

27. Variación de la textura de tres parafangos, tras sucesivas esterilizaciones térmicas, utilizados en balnearios españoles para el tratamiento de enfermedades del aparato locomotor en Libro de resúmenes del II Congreso Iberoamericano de Peloides

Madrid: CERSA. 2010, 32-33

ISBN 978-84-614-2315-6

Lanjarón. 14-16/07/2010

28. Características físicas del peloide de las Termas "Antonio Carlos" (Poços De Caldas - Minas Gerais - Brasil) en Libro de resúmenes del II Congreso Iberoamericano de Peloides

Madrid: CERSA. 2010, 34-35

ISBN 978-84-614-2315-6

Lanjarón. 14-16/07/2010 
29. Caracterización mineralógica y química de peloides españoles y argentinos. Evaluación de elementos traza potencialmente tóxicos en Libro de resúmenes del II Congreso Iberoamericano de Peloides

Madrid: CERSA. 2010, 37-38

ISBN 978-84-614-2315-6

Lanjarón. 14-16/07/2010

30. Estudio in vitro de la trasferencia de elementos beneficiosos mediante la aplicación de peloides en Libro de resúmenes del II Congreso Iberoamericano de Peloides

Madrid: CERSA. 2010, 39-40

ISBN 978-84-614-2315-6

Lanjarón. 14-16/07/2010

31. Estudio multidisciplinar de la aplicación de arcillas en Balnearios y Talasos. Proyecto TRA2009_0240 en Libro de resúmenes del II Congreso Iberoamericano de Peloides

Madrid: CERSA. 2010, 56-57

ISBN 978-84-614-2315-6

Lanjarón. 14-16/07/2010

32. Valoración del tratamiento balneoterápico y peloterápico de la Gonartrosis en el Balneario de Lanjarón en Libro de resúmenes del II Congreso Iberoamericano de Peloides

Madrid: CERSA. 2010, 63-64

ISBN 978-84-614-2315-6

Lanjarón. 14-16/07/2010

33. Características físicas de peloides elaborados a partir de bentonitas utilizadas en el proceso de elaboración del vino de Jerez de la Frontera en Libro de resúmenes del II Congreso Iberoamericano de Peloides

Madrid: CERSA. 2010, 69-70

ISBN 978-84-614-2315-6

Lanjarón. 14-16/07/2010

34. Estudio analítico del agua marina empleada para la maduración de los peloides del Thalasso Center - Thalasia (San Pedro de Pinatar - Murcia) en Libro de resúmenes del II Congreso Iberoamericano de Peloides

Madrid: CERSA. 2010, 71-72

ISBN 978-84-614-2315-6

Lanjarón. 14-16/07/2010 
35. Características físicas del peloide elaborado con el agua mineromedicinal Lanjarón-Salado (Lanjarón - Granada) en Libro de resúmenes del II Congreso Iberoamericano de Peloides

Madrid: CERSA. 2010, 73-74

ISBN 978-84-614-2315-6

Lanjarón. 14-16/07/2010

36. Estudio crítico de los trabajos sobre peloides publicados en la revista "Voprosy Kurortologii Fizioterpii i Lechbenoi Fizicheskoi Kultury" en los ultimos 10 Años en Libro de resúmenes del II Congreso Iberoamericano de Peloides Madrid: CERSA. 2010, 85-86

ISBN 978-84-614-2315-6

Lanjarón. 14-16/07/2010

37. Las aguas mineromedicinales en la maduración de peloides tradicionales en Libro de resúmenes del II Congreso Iberoamericano de Peloides

Madrid: CERSA. 2010, 88-89

ISBN 978-84-614-2315-6

Lanjarón. 14-16/07/2010

38. Acciones dermatológicas del sedimento de las aguas mineromedicinales lanjarón-capuchina en Libro de resúmenes del II Congreso Iberoamericano de Peloides

Madrid: CERSA. 2010, 90-90

ISBN 978-84-614-2315-6

Lanjarón. 14-16/07/2010

39. Evaluacion de la talasoterapia en relación al tratamiento de la degeneración osteoarticular (gonartrosis). Determinación de los índices de eficacia y patrones de aplicación terapéutica en Libro de resúmenes del II Congreso Iberoamericano de Peloides

Madrid: CERSA. 2010, 91-92

ISBN 978-84-614-2315-6

Lanjarón. 14-16/07/2010

40. Evaluación de los cambios en la piel tras la aplicación de una emulsión facial con sales de la capuchina mediante métodos de bioingeniería cutánea en Libro de resúmenes del II Congreso Iberoamericano de Peloides

Madrid: CERSA. 2010, 93-94

ISBN 978-84-614-2315-6

Lanjarón. 14-16/07/2010 
41. El agua mineral natural y tensión arterial en Libro de resúmenes del VII Congreso Internacional de nutrición, alimentación y dietética Madrid: SPRIM. 2011, 11-12

ISBN 978-84-694-1867-3

Madrid. 30-01/03-04/2011

42. Aporte de calcio y magnesio de las aguas mineromedicinales durante el tratamiento hidropínico

Nutrición clínica y dietética hospitalaria. 2011; 31(supl. 1): 63

ISSN 0021-6057

VII Congreso Internacional de nutrición, alimentación y dietética

Madrid. 30-01/03-04/2011

43. When volcanic Waters are beneficial to health en Geological and Medical Sciences for a safer Environment

Bari: Digilabs Pub. 2011, 6

ISBN 978-88-7522-041-9

GeoMed2011 - 4th International Conference on Medical Geology

Bari (Italia).20-25/09/2011

44. Comportamiento de la Motilidad ciliar en pacientes tratados con aguas minerales de la Villa Termal de Copahue, Neuquen, Argentina en $\mathbf{1}^{\circ}$ Congreso Internacional de Termalismo: libro de resúmenes

Neuquén: Universidad Nacional del Comahue. 2011, 20-22

ISBN 978-987-604-255-0

$1^{\circ}$ Congreso Internacional de Termalismo

Neuquén (Argentina).27-28/10/2011

45. Estudio de las aguas minerales de la Provincia de Neuquén Argentina en $\mathbf{1}^{\mathbf{0}}$ Congreso Internacional de Termalismo: libro de resúmenes

Neuquén: Universidad Nacional del Comahue. 2011, 32-33

ISBN 978-987-604-255-0

$1^{\circ}$ Congreso Internacional de Termalismo

Neuquén (Argentina).27-28/10/2011

46. Balneoterapia (Agua mineromedicinal clorurada-ferruginosa) en la osteortrosis de rodilla en $\mathbf{1}^{\mathbf{0}}$ Congreso Internacional de Termalismo: libro de resúmenes

Neuquén: Universidad Nacional del Comahue. 2011, 58-59

ISBN 978-987-604-255-0

$1^{\circ}$ Congreso Internacional de Termalismo

Neuquén (Argentina).27-28/10/2011 
47. Rasgos Socio-Demográficos de los bañistas de las Termas de Copahue. Estudio preliminar en $\mathbf{1}^{\circ}$ Congreso Internacional de Termalismo: libro de resúmenes

Neuquén: Universidad Nacional del Comahue. 2011, 60-62

ISBN 978-987-604-255-0

$1^{\circ}$ Congreso Internacional de Termalismo

Neuquén (Argentina).27-28/10/2011

48. Estudio Características físicas del peloide de Caldas de Bohí en $\mathbf{1}^{\mathbf{0}}$ Congreso Internacional de Termalismo: libro de resúmenes

Neuquén: Universidad Nacional del Comahue. 2011, 65-67

ISBN 978-987-604-255-0

$1^{\circ}$ Congreso Internacional de Termalismo

Neuquén (Argentina).27-28/10/2011

49. Caracteristicas fisicas del peloide de la laguna del Chancho de Copahue en $\mathbf{1}^{\mathbf{0}}$ Congreso Internacional de Termalismo: libro de resúmenes

Neuquén: Universidad Nacional del Comahue. 2011, 68-70

ISBN 978-987-604-255-0

$1^{\circ}$ Congreso Internacional de Termalismo

Neuquén (Argentina).27-28/10/2011

50. Message of the President of the organising committee en Medical Hydrology and Balneology: Environmental Aspect. Balnea. 2012; 6: 25-26

ISBN 978-84-669-3482-4

38 World Congress of the Internacional Society of Medical Hydrology and Climatology.

Lanjarón. 20-23/06/2012

51. State of the art, Health Resort Medicine in Spain en Medical Hydrology and Balneology: Environmental Aspect. Balnea. 2012; 6: 58-59

ISBN 978-84-669-3482-4

38 World Congress of the Internacional Society of Medical Hydrology and Climatology.

Lanjarón. 20-23/06/2012

52. Study of ciliary motility in patients treated with mineral waters from "Las Termas de Copahue", Neuquén, Argentina. en Medical Hydrology and Balneology: Environmental Aspect. Balnea. 2012; 6: 64-65

ISBN 978-84-669-3482-4

38 World Congress of the Internacional Society of Medical Hydrology and Climatology. 
Lanjarón. 20-23/06/2012

53. Is thalassotherapy simply a type of climatotherapy? no, certainly, it's not en Medical Hydrology and Balneology: Environmental Aspect. Balnea. 2012; 6: $102-103$ ISBN 978-84-669-3482-4

38 World Congress of the Internacional Society of Medical Hydrology and Climatology.

Lanjarón. 20-23/06/2012

54. Variation of the instrumental texture of peloids as a function of the water content en Medical Hydrology and Balneology: Environmental Aspect. Balnea. 2012; 6: 147-149

ISBN 978-84-669-3482-4

38 World Congress of the Internacional Society of Medical Hydrology and Climatology.

Lanjarón. 20-23/06/2012

55. Biophysical skin effects of peloids according to their maturity time en Medical Hydrology and Balneology: Environmental Aspect. Balnea. 2012; 6: 169170

ISBN 978-84-669-3482-4

38 World Congress of the Internacional Society of Medical Hydrology and Climatology.

Lanjarón. 20-23/06/2012

56. Balneotherapy and mud-therapy in knee osteoarthritis treatment en Medical Hydrology and Balneology: Environmental Aspect. Balnea. 2012; 6: 183184

ISBN 978-84-669-3482-4

38 World Congress of the Internacional Society of Medical Hydrology and Climatology.

Lanjarón. 20-23/06/2012

57. The Bahia 2011 Seniors study. patterns of Hydration in the elderly in Spain en Medical Hydrology and Balneology: Environmental Aspect. Balnea. 2012; 6: $214-215$ ISBN 978-84-669-3482-4

38 World Congress of the Internacional Society of Medical Hydrology and Climatology.

Lanjarón. 20-23/06/2012 
58. Nitrates in spanish waters: natural mineral water and tap water en Medical Hydrology and Balneology: Environmental Aspect. Balnea. 2012; 6: 220222

ISBN 978-84-669-3482-4

38 World Congress of the Internacional Society of Medical Hydrology and Climatology.

Lanjarón. 20-23/06/2012

59. Cardiovascular risk factors in patients of the social thermal program in Lanjarón Spa en Medical Hydrology and Balneology: Environmental Aspect. Balnea. 2012; 6: 273-274

ISBN 978-84-669-3482-4

38 World Congress of the Internacional Society of Medical Hydrology and Climatology.

Lanjarón. 20-23/06/2012

60. Water Journeys (II): Granada Spas and Springs through Travelers' and Hydrologists' eyes en Medical Hydrology and Balneology: Environmental Aspect. Balnea. 2012; 6: 285-286

ISBN 978-84-669-3482-4

38 World Congress of the Internacional Society of Medical Hydrology and Climatology.

Lanjarón. 20-23/06/2012

61. Balneology Research in Spain en Medical Hydrology and Balneology: Environmental Aspect. Balnea. 2012; 6: 291-292

ISBN 978-84-669-3482-4

38 World Congress of the Internacional Society of Medical Hydrology and Climatology.

Lanjarón. 20-23/06/2012

62. Does balneology still have gynecologic indications? en Medical Hydrology and Balneology: Environmental Aspect. Balnea. 2012; 6: 329

ISBN 978-84-669-3482-4

38 World Congress of the Internacional Society of Medical Hydrology and Climatology.

Lanjarón. 20-23/06/2012

63. Spa, hydrotherapy's treatment, and quality of life en Medical Hydrology and Balneology: Environmental Aspect. Balnea. 2012; 6: 359-360

ISBN 978-84-669-3482-4 
38 World Congress of the Internacional Society of Medical Hydrology and Climatology.

Lanjarón. 20-23/06/2012

64. Quality of life and thermal cure en Medical Hydrology and Balneology: Environmental Aspect. Balnea. 2012; 6: 361-362

ISBN 978-84-669-3482-4

38 World Congress of the Internacional Society of Medical Hydrology and Climatology.

Lanjarón. 20-23/06/2012

65. Thermotherapy applications in spanish resorts using peloids and parafangos en Medical Hydrology and Balneology: Environmental Aspect. Balnea. 2012; 6: $385-386$ ISBN 978-84-669-3482-4

38 World Congress of the Internacional Society of Medical Hydrology and Climatology.

Lanjarón. 20-23/06/2012

66. Study of the liquid phase of peloids prepared with mineral waters from balneario de Lanjarón (Granada, Spain) en Medical Hydrology and Balneology: Environmental Aspect. Balnea. 2012; 6: 389-390

ISBN 978-84-669-3482-4

38 World Congress of the Internacional Society of Medical Hydrology and Climatology.

Lanjarón. 20-23/06/2012

67. Cardiorespiratory response to Thalassotherapy on stroke patients en Medical Hydrology and Balneology: Environmental Aspect. Balnea. 2012; 6: 411412

ISBN 978-84-669-3482-4

38 World Congress of the Internacional Society of Medical Hydrology and Climatology.

Lanjarón. 20-23/06/2012

68. Talassotherapy on stroke rehabilitation. Review of classical contraindications, complications. Comparison with a traditional Spa in Murcia en Medical Hydrology and Balneology: Environmental Aspect. Balnea. 2012; 6: 413-414 ISBN 978-84-669-3482-4

38 World Congress of the Internacional Society of Medical Hydrology and Climatology.

Lanjarón. 20-23/06/2012 
69. Beneficial effects of Thalassotherapy in upper limb hemiparesis after stroke en Medical Hydrology and Balneology: Environmental Aspect. Balnea. 2012; 6: $415-416$ ISBN 978-84-669-3482-4 38 World Congress of the Internacional Society of Medical Hydrology and Climatology.

Lanjarón. 20-23/06/2012

70. Health workers knowledge about medical hydrology in Spain en Medical Hydrology and Balneology: Environmental Aspect. Balnea. 2012; 6: 436-437 ISBN 978-84-669-3482-4

38 World Congress of the Internacional Society of Medical Hydrology and Climatology.

Lanjarón. 20-23/06/2012

71. Health workers knowledge about medical hydrology in Argentina en Medical Hy-drology and Balneology: Environmental Aspect. Balnea. 2012; 6: 438439

ISBN 978-84-669-3482-4

38 World Congress of the Internacional Society of Medical Hydrology and Climatology.

Lanjarón. 20-23/06/2012

72. Medico-legal aspects of the Medical Hydrology in Spain en Medical Hydrology and Balneology: Environmental Aspect. Balnea. 2012; 6: 446 ISBN 978-84-669-3482-4

38 World Congress of the Internacional Society of Medical Hydrology and Climatology.

Lanjarón. 20-23/06/2012 


\section{CONTRIBUCIONES A CONGRESOS}

Nacionales

1. IV Jornadas de Rehabilitación Geriátrica. Montanejos (Castellón) 10-11/11/2000.

- Ponencia invitada:

Programas de rehabilitación en balnearios de la Unión Europea

2. Congreso Nacional de la Sociedad Española de Hidrología Médica. Archena (Murcia) $01-02 / 12 / 2000$.

- Miembro del Comité de Honor

- Comunicaciones orales (16):

Aguas envasadas de Lanjarón: evolución a lo largo del tiempo a través de sus etiquetas

Alteraciones de los oligoelementos esenciales en humanos, legislación y recomendaciones dietéticas

Análisis fisicoquímico del agua Fita-Santa Fe: comparación de análisis anteriores

Baños de Montemayor. Rehabilitación de un Balneario

La estética termal en el Balneario de Lanjarón: revitalizador capuchina facial

Efectos de la ingesta de aguas minerales naturales Lanjarón-San Vicente sobre la morbilidad de pacientes hemodializados

Gonartrosis y Termalismo Social en el Balneario de Lanjarón

Oligoelementos: conceptos y generalidades

Oligoelementos esenciales: biodisponibilidad y papel fisiológico

Los peloides del balneario de Archena: estudio químico-fisico, de microscopía electrónica analítica y barrido

Perfil sociodemográfico del programa de Balneoterapia de la Junta de Extremadura en Montemayor

Perfil socio-demográfico del programa de la población balnearia de Lanjarón (Granada) beneficiaria del programa de Termalismo Social

Repercusión en el gasto farmacéutico por la utilización del agua mineromedicinal de Carabaña en una residencia de ancianos

Resultados de la valoración en el análisis sistemático de la orina de pacientes sometidos a cura hidropónica en el Balneario de Cervantes

Selenio. Funciones. Déficit y Toxicidad. Patología asociada

Zinc, Cobre y Manganeso. Funciones. Déficit y Toxicidad. Patología asociada

- Posters (6)

Estudio de la curva de temperatura de peloides artificiales de origen inorgánico

Análisis de las aguas mineromedicinales de Gerona y Lérida. Siglo XIX

Análisis de las aguas mineromedicinales de Murcia y Almería. Siglo XIX

Análisis de las aguas mineromedicinales de Jaén. Siglo XIX

Análisis de las aguas mineromedicinales de Cantabria y La Rioja. Siglo XIX

Título: Análisis de las aguas mineromedicinales de Extremadura. Siglo XIX 
3. XI Reunión Científica de la Sociedad Canaria de Reumatología. Gran Canarias 1920/04/2002.

- Comunicación oral:

Talasoterapia. Aspectos generales y perspectivas en el tratamiento del enfermo reumático

4. Jornadas sobre "Las aguas minero-medicinales del manantial de los Baños". Ariño (Teruel) 26-27/04/2002.

- Ponencias invitadas (3):

Termalismo y turismo de salud. Situación actual y perspectivas de desarrollo

Tendencias actuales de la cura balnearia

Historia de los baños de Ariño a través de sus análisis

5. XXIV Congreso de la Sociedad Española de Farmacología. Toledo 22-25/09/2002.

- Poster: Actividad farmacológica de las aguas minerales de Firgas. Islas Canarias.

6. Congreso Nacional de la Sociedad Española de Hidrología Médica. Puente Viesgo (Cantabria). 23-25/11/2002

- Miembro del Comité de Honor

- Presidencia de Sesión

- Comunicaciones orales (3):

Actividad cardiovascular de las aguas minerales de Firgas (Islas Canarias)

Estudio del azufre reducido de las aguas mineromedicinales españolas

- Posters (1)

Las aguas mineromedicinales de Lanjarón-Capuchina en afecciones dermatológicas

7. II Congreso de la Sociedad Española de Medicina Antienvejecimiento y Longevidad. Madrid 09/05/2003.

- Ponencia invitada:

Antioxidantes, crenoterapia y Antienvejecimiento "Hidrología Médica y antienvejecimiento"

8. Sesión Científica de la Sociedad Española de Hidrología Médica. Madrid 12/06/2003.

- Ponencia invitada:

El Olimpo y el Mar

9. XXV Congreso de la Sociedad Española de Farmacología. Cádiz 08-11/10/2003.

- Poster:

Actividad gastrointestinal de las aguas minerales de Firgas. Islas Canarias.

10. II Jornada Nacional de Hidrología Médica. Caldes Malavella (Girona) 07/11/2003.

- Ponencia invitada:

Redescubrir los efectos beneficiosos del agua 
11. XXVI Congreso de la Sociedad Española de Farmacología. Salamanca 2629/09/2004.

- Poster:

Actividad neurológica y toxicológica de las aguas minerales de Firgas. Islas Canarias.

12. XVI Congreso Nacional SEMERGEN. Granada 13-16/10/2004.

- Ponencia invitada:

Taller de Hidrología Médica: importancia de la balneoterapia en la consulta del médico de Atención Primaria

13. Congreso Nacional de la Sociedad Española de Hidrología Médica. Alange (Badajoz). $10-12 / 12 / 2004$

- Comunicaciones orales (6):

Apuntes para la Historia reciente del Termalismo extremeño

Perfil sanitario y crenoterápico de los termalistas del Balneario de Baños de Montemayor durante la temporada 2004

Relación entre la composición de un peloide y su comportamiento térmico

Los peloides del balneario de Caldes de Boí: estudio químico-físico, de microscopía electrónica analítica y barrido

Situación de la peloidoterapia en Europa

Caracterización Física y Físico-química de Peloides Españoles. Estudio de su Variabilidad

14. Reunión sobre normalización y cualificación de arcillas usadas en salud - CSIC. Madrid 15/05/2005.

- Ponencia invitada:

Los Peloides en los Balnearios Españoles. Experiencia de la Cátedra de Hidrología Médica

15. Jornadas Turismo Salud y Belleza. Retamar (Almería) 17-18/01/2007.

- Ponencia invitada:

Tratamientos Hidrotermales

16. Jornadas Turismo Salud y Belleza. Alhama de Granada (Granada) 14-15/11/2007.

- Ponencia invitada:

Antecedentes históricos de los balnearios

17. Acto de presentación del Instituto de Investigación Agua y Salud. Madrid 23/06/2008.

- Ponencia invitada:

Presentación de las "Memorias de las Aguas Minero Medicinales españolas (siglos $X I X y X X)$ 
18. ExpoZaragoza 2008 - Tribuna del Agua: El agua, un nutriente esencial para la vida. Zaragoza 09-10/07/2008.

- Ponencia invitada:

Mineralización de las aguas: distintos origenes y aplicaciones

19. I Jornadas de Termalismo de Andalucía. Lanjarón-Atarfe (Granada) 24-25/09/2008.

- Ponencia invitada:

El valor terapéutico y el potencial de las aguas mineromedicinales y termales de Andalucía

20. VII Encuentro de Entidades Locales con Aguas Minerales y Termales. Montanejos (Castellón) 13-14/11/2008.

- Ponencia invitada:

La investigación científica en Hidrología Médica y su impacto en el desarrollo estratégico de las Villas Termales. Experiencia y perspectiva en España

21. Xornada de difusión de peloides termais: Avances na investigación e aplicación de peloides termais. La Toja (Pontevedra) 27-28/11/2008.

- Ponencia invitada:

Antecedentes y situación actual de la peloterapia en Europa

22. Jornada sobre Aguas Minerales y Termales: un recurso minero, socio-económico y ambiental. Linares (Jaén) 22/05/2009.

- Ponencia invitada:

Efectos beneficiosos de las aguas minerales en la salud humana

23. Congreso Nacional de la Sociedad Española de Hidrología Médica. Ourense 16$17 / 10 / 2009$

- Ponencia invitada (1):

Presentación del $2^{\circ}$ Vademécum de Aguas Mineromedicinales españolas

- Posters (3)

Estudio de la textura del peloides de marino del Centro Thalasia (Murcia)

Estudio de los peloides del Mar Menor (Murcia): características y propiedades

Comparación de la textura de três parafangos utilizados em Balnearios españoles

24. VII Jornadas Interuniversitarias de Terapia Ocupacional. Madrid 17/11/2009

- Miembro del Comité Cientíco

25. II Encuentro de Termalismo de Andalucía. Canena (Jaén) 19-20/11/2009.

- Ponencia invitada:

Las aguas mineromedicinales de Andalucía en el Vademécum de aguas mineromedicinales españolas 
26. Jornadas Valores Turísticos de la Balneoterapia. Lanjarón (Granada) 17/03/2010.

- Ponencia invitada:

El Valor de los Tratamientos Termales en la Naturaleza

27. I Jornada Técnica Municipal del Día Mundial del Agua. Madrid 21/03/2011.

- Ponencia invitada:

Las aguas envasadas y sus efectos en la salud

28. V Jornada. Programa Medio Ambiente, Economía y Salud. Zaragoza 03/11/2011.

- Ponencia invitada:

Aguas que nutren, aguas que curan. Evidencia cientifica

29. Encuentro médico ASEXVE 2011. Horche (Guadalajara) 26/11/2011.

- Ponencia invitada:

Las Aguas Minerales en afecciones de riñón y vías urinarias

30. V Centenario del Hospital General de Valencia - Ciclo de Conferencias Históricas y Culturales. Valencia 28/11/2011.

- Ponencia invitada:

La evidencia científica en Hidrología Médica

31. Acto Académico de Conmemoración del centenario de la creación de la Cátedra de Hidrología Médica e inauguración de la Exposición de "Cien años haciendo ciencia: la Cátedra de Hidrología Médica de la Facultad de Medicina de la Universidad Complutense (1912-2012).”. Madrid 17/04/2012.

- Miembros del Comité Organizador

- Ponencias invitadas (2):

La Cátedra de Hidrología Médica y los análisis de aguas minerales

La Cátedra de Hidrología Médica y la Escuela Profesional de Hidrología Médica e Hidroterapia

Internacionales

1. XVII Jornada Mundial de Termalismo y $\mathbf{1}^{\circ}$ Congreso y Muestra Termal e Industrial. Pereira (Colombia) 23-25/04/2001.

- Ponencias invitadas (2):

Curas balnearias: Agente terapéutico y turístico

Usos y aplicaciones de lodos y peloides (Dermatología Termal- Talasoterapia)

2. 34 World Congreso of the Internacional Society of Medical Hydrology and Climatology. Budapest-Hévíz (Hungría) 14-19/10/2002.

- Presidencia de Sesión

- Ponencia invitada (1):

Physiology of aquatic therapy: Resistance factors 
- Comunicaciones orales (3):

Balneotherapy at "Puente Viesgo's Spa"

How does the pharmaceutical expenses affect by the use of Carabaña's mineral water in geriatric center

Effect of Lanjarón-San Vicente mineral water ingested, on morbility of hemodialized patients

- Posters (1):

Lanjarón spa: capuchina mineral waters - "revitalizador facial”

3. First World Congress of Thalassotherapy. Agadir (Marruecos) 24-26/01/2003.

- Ponencia invitada:

The Olympus and the Sea

4. Termatalia 2003 - Jornadas Termatalia 2003. Ourense $31-02 / 10-11 / 2003$.

- Ponencia invitada:

El agua en bebida, propiedades

5. Congreso Transpirenaico de Medicina Física y Rehabilitación - Reunión Científica Conjunta de las Sociedades Española y Francesa de Hidrología Médica. Toulouse (Francia) 21-22/11/2003.

- Presidencia de Sesión

- Comunicaciones orales (2):

Trealtement Thermal de personnes agees en France et en Espagne

25 années de l'Ecole d'Hydrologie médicale et d'Hydrothérapie de Madrid

6. II Congreso Europeo de Medicina Naturista. Zaragoza 07-09/05/2004.

- Ponencia invitada:

Balneoterapia y enfermedad cardíaca

7. Congreso Ibérico de Termalismo. Santa María da Feira (Portugal) 04-06/11/2004.

- Ponencia invitada:

Presentación del Vademecum de Aguas Mineromedicinales españolas

8. 3rd International Symposium on thermal muds in europe. Dax (Francial) 2527/11/2004.

- Ponencia invitada:

State of the art of mud therapy in Spain

9. I Foro ibérico sobre aguas envasadas y balnearios. Madrid 15-16/03/2005.

- Comunicación oral:

La Hidrología Médica en los Establecimientos Balnearios 
10. Termatalia 2005 - Jornadas Técnicas 2005. Ourense 30-02/09-10/2005.

- Miembro del Comité Organizador

- Ponencia invitada: Agua en Bebida

11. Premières Rencontres Internationales de l'Institut du Thermalisme de l'Université Victor Segalen Bordeaux 2. Dax (Francial) 02-03/12/2005.

- Ponencias invitadas (3):

La recherche thermale

La formation aux métiers du thermalisme

De l'information á la documentation thermales

12. Jornadas Internacionales de Termalismo en Dermatología. Copahue (Argentina) 31-02/03-04/2006.

- Ponencias invitadas (2):

Formación de Médicos especialistas en Hidrología Médica

Termalismo y Dermatología en el Mundo

13. IV Congreso Europeo de Medicina Naturista. Zaragoza 12-14/05/2006.

- Ponencia invitada:

Hidroterapia y Balneoterapia en el Niño

14. 15th European Congreso of Pfysical and Rehabilitation Medicine. Madrid 1620/05/2006.

- Comunicación oral (1):

Functional Reeducation in spanish Spa

- Posters (1):

Natural Mineral spanish waters as source of calcium and magnesio

15. 35 World Congreso of the Internacional Society of Medical Hydrology and Climatology. Estambul (Turquía) 06-10/06/2006.

- Presidencia de Sesión

- Ponencias invitadas (2):

Medical Hydrology and Climatology in Spain

Mineral Natural Waters Bottled. Drinking Cure

- Comunicaciones orales (1):

Registered incident during IMSERSO Social Thermalism Program

- Posters (2):

Therapeutic Clays, Muds and Peloids from Termas Copahué - Neuquén (Argentina): characteristics and properties

Spas: Services and Health Centres in Health Tourism Establisments 
16. Termatalia 2006 - Jornadas Técnicas: Hidrología Médica. Ourense 27-29/10/2006.

- Ponencia invitada:

La Balneoterapia, medicina del bienestar

17. 2emes Rencontres Internationales de l'Institut du Thermalisme de l'Université Victor Segalen Bordeaux 2. Dax (Francial) 08/06/2007.

- Ponencia invitada:

Le thermalisme en Espagne

18. III Congresso Ibérico de Termalismo. Estoril (Portugal) 11-12/09/2007.

- Ponencia invitada:

Saúde e Medicina Termal

19. I Congreso Iberoamericano de Peloides. Baiona (Pontevedra) 04-07/11/2007.

- Miembros del Comité Organizador

- Miembros del Comité Científico

- Presidencia de Sesiones

- Ponencias invitadas (2): Antecedentes historicos de la utilización de los peloides y situación actual Textura y granulometría de los peloides

- $\operatorname{Posters~(1):~}$

Curva de enfriamiento de peloides artificiales

20. PROTERMAL Tendencias Termales y Ámbito Legal. Madrid 28-29/03/2008.

- Ponencia invitada:

El agua en el ámbito del wellness

21. V Congreso Europeo de Medicina Naturista. Zaragoza 16-18/05/2008

- Ponencia invitada:

La enseñanza de hidrología en la Universidad Complutense de Madrid (España). Antecedentes y situación actual

22. 36 World Congreso of the Internacional Society of Medical Hydrology and Climatology. Oporto (Portugal) 25-28/06/2008.

- Miembro del Comité Científico

- Presidencia de Sesión

- Ponencias invitadas (1):

Capacities to manage a thermal health centre

- Comunicaciones orales (1):

Cachucha Beach sea peloid's physical properties (Puerto Real - Spain)

- Posters (3):

Therapeutic mud from "Antonio Carlos Thermas" - Poços de Caldas (Minas Gerais - Brasil): characteristics and properties

Occupational therapy and Thermal Stations 
General doctor's knowlege on: Medical Hydrology, Balneotherapy and SocialHealth Thermalism Programs

23. Termatalia 2008 - Jornadas Técnicas: III Encuentro Internacional sobre Agua y Termalismo. Ourense 02/10/2008.

- Ponencia invitada:

Los Peloides Terapéuticos. Experiencia de la Cátedra de Hidrología Médica (Universidad Complutense)

24. Seminario Internacional. Avances en Hidrología Médica \& Termalismo. Buenos Aires (Argentina) 24-25/10/2008.

- Ponencia invitada :

Termalismo y Laboratorio: Aguas y Fangos

25. IX Radiation Physics \& Protection Conference. El Cairo (Egipto) 15-19/11/2008.

- Comunicación oral:

Radon and Radioactivity in Spain Spas of Different Geological Formations

26. Meeting internazionale sul termalismo: confronto ítalo-franco-ispano nei Campi Flegrei. Baia-Bacoli (Italia) 12-13/06/2009.

- Ponencia invitada:

Termalismo e ricerca scientifica in Spagna

27. I ${ }^{0}$ Simpósio brasileiro de Crenologia e Hidrologia Médica. Águas de São Pedro (Brasil) 29-02/09-10/2009.

- Ponencias invitadas (3):

O ensino da Hidrologia Médica nas Universidades européias

Conceitos e atualizações em Hidrologia Médica

Fangoterapia

28. Termatalia 2009 - Jornadas Técnicas: IV Encuentro Internacional sobre Agua y Termalismo. Ourense 15/10/2009.

- Miembro del Comité Asesor

- Ponencia invitada:

Estado de las Aguas Mineromedicinales en España

29. Encontro Internacional de Termalismo y Turismo Termal \& III Fórum Ibérico de Aguas Engarrafadas e Termalismo. Furnas - Açores (Portugal) 02-06/11/2009.

- Miembro del Comité Científico

- Ponencia invitada:

Composición Química de las Aguas y Aspectos Sanitarios 
30. 2ème Symposium Européen de Recherche Thermale - 3èmes Rencontres Internationales de l'Institut du Thermalisme 2emes. Dax (Francia) 27/11/2009.

- Ponencia invitada:

Projet européen TERMARED, réseau européen thermal

31. Congresso da Sociedade Portuguesa de Hidrologia Médica. Chaves (Portugal) 0305/06/2010.

- Miembro del Comité Científico

- Presidencia de Sesión

- Ponencia invitada:

Hidrogeologia Médica (parafangos, pelóides, psamoterapia)

32. 37 World Congreso of the Internacional Society of Medical Hydrology and Climatology. París (Francia) 23-26/06/2010.

- Miembro del Comité Científico

- Presidencias de Sesión

- Ponencias invitadas (1):

Medical hydrology teaching adapted to European higher education area

- Comunicaciones orales (2):

Bottled natural mineral water and health

Thermal treatment for elderly in a Spanish and French balneary

- Posters (7):

Skin response to osmotic cosmetics elaborated with mud made from chlorided ferruginous mineral water

Socio-demographical characteristics of patients attending the Copahue hot springs (Neuquen-Argentine), Preliminary study

Effectiveness of aquatic therapy in the treatment of fibromyalgia syndrome

Balneology (chlorided-ferruginous mineral water) in knee osteoarthritis treatment

Evaluation of thalasotherapy in relation to the treatment of fibromialgia in comparison to the physical medicine techniques. Determination of the effectiveness and therapeutic patterns of application

Aquatic therapy in osteoporosis: a systematic review

Study of the characteristics and properties of Thalasia's (Murcia) salt water peloid

33. II Congreso Iberoamericano de Peloides. Lanjarón (Granada) 14-16/07/2010.

- Presidencia del Comité Organizador

- Presidencia del Comité Científico

- Presidencias de Sesiones

- Comunicaciones orales (8):

Estudio de las aguas mineromedicinales del Balneario de Lanjarón y su idoneidad para la maduración de peloides

Estudio analítico de las aguas de maduración de los peloides y sedimentos de las termas de Copahue (Neuquén - Argentina) 
Variación de la textura de tres parafangos, tras sucesivas esterilizaciones térmicas, utilizados en balnearios españoles para el tratamiento de enfermedades del aparato locomotor

Características físicas del peloide de las Termas "Antonio Carlos" (Poços De Caldas - Minas Gerais - Brasil)

Caracterización mineralógica y química de peloides españoles y argentinos. Evaluación de elementos traza potencialmente tóxicos

Estudio in vitro de la trasferencia de elementos beneficiosos mediante la aplicación de peloides

Estudio multidisciplinar de la aplicación de arcillas en Balnearios y Talasos. Proyecto TRA2009 0240

Valoración del tratamiento balneoterápico y peloterápico de la Gonartrosis en el Balneario de Lanjarón

- Posters (8):

Características físicas de peloides elaborados a partir de bentonitas utilizadas en el proceso de elaboración del vino de Jerez de la Frontera

Estudio analítico del agua marina empleada para la maduración de los peloides del Thalasso Center - Thalasia (San pedro de Pinatar-Murcia)

Características físicas del peloide elaborado con el agua mineromedicinal Lanjarón-Salado (Lanjarón - Granada)

Estudio crítico de los trabajos sobre peloides publicados en la revista "Voprosy Kurortologii Fizioterpii i Lechbenoi Fizicheskoi Kultury” en los ultimos 10 Años

Las aguas mineromedicinales en la maduración de peloides tradicionales Acciones dermatológicas del sedimento de las aguas mineromedicinales lanjaróncapuchina

Evaluacion de la talasoterapia en relación al tratamiento de la degeneración osteoarticular (gonartrosis). Determinación de los índices de eficacia y patrones de aplicación terapéutica

Evaluación de los cambios en la piel tras la aplicación de una emulsión facial con sales de la capuchina mediante métodos de bioingeniería cutánea

34. $2^{\circ}$ Simpósio brasileiro de Crenologia e Hidrologia Médica. Natal (Brasil) 1315/10/2010.

- Ponencia invitada:

Talassoterapia

35. Termatalia 2010 - Jornadas Técnicas: V Encuentro Internacional sobre Agua y Termalismo. Ourense 14/10/2010.

- Miembro del Comité Asesor

36. VII Congreso Internacional de Nutrición, Alimentación y Dietética. Madrid 3001/03-04/2011.

- Ponencia invitada (1):

Agua Mineral Natural y Tensión Arterial 
- Poster (1):

Aporte de calcio y magnesio de las aguas mineromedicinales durante el tratamiento hidropínico

37. Congresso da Sociedade Portuguesa de Hidrologia Médica. Monte Real (Portugal) $10-11 / 06 / 2011$.

- Miembro del Comité Científico

- Ponencia invitada:

Investigação em Hidrologia: a nossa experiência

38. $3^{\circ}$ Simpósio brasileiro de Crenologia e Hidrologia Médica. Rio de Janeiro (Brasil) $13-15 / 09 / 2011$.

- Ponencias invitadas (2):

Aguas Minerales envasadas y sus repercusiones en la salud

Investigación Científica en Hidrologia Médica

39. 4 Th International Conference on Medical Geology. Bari (Italia) 20-25/09/2011.

- Comunicación oral:

When volcanic Waters are beneficial to health

40. Termatalia 2011 - Jornadas Técnicas: VI Encuentro Internacional sobre Agua y Termalismo. Ourense 22/09/2010.

- Miembro del Comité Asesor

- Ponencias invitadas (2):

¿Es igual el agua del grifo que el agua envasada? No, sin duda no.

Presentación del $38^{\circ}$ Congreso de la Sociedad Internacional de Hidrología Médica y Climatología - ISMH 2012

41. $\mathbf{1}^{\circ}$ Congreso Internacional de Termalismo. Neuquén (Argentina) 27-28/10/2011.

- Ponencias invitadas (1):

La investigación actual en Hidrología Médica a nivel Mundial

- Comunicaciones orales (2):

Comportamiento de la Motilidad ciliar en pacientes tratados con aguas minerales de la Villa Termal de Copahue, Neuquen, Argentina

Estudio de las aguas minerales de la Provincia de Neuquén Argentina

- Posters (4):

Balneoterapia (Agua mineromedicinal clorurada-ferruginosa) en la osteortrosis de rodilla

Rasgos Socio-Demográficos de los bañistas de las Termas de Copahue. Estudio preliminar

Estudio Características fisicas del peloide de Caldas de Bohí

Características fisicas del peloide de la laguna del Chancho de Copahue 
42. Jornadas Profesionales de Termalismo. Ourense 07-08/06/2012.

- Ponencias invitadas (2):

Presentación $38^{\circ}$ Congreso Mundial de la ISMH

Uso terapéutico - El valor del agua mineromedicinal como elemento diferenciador y motor económico

43. Acto Académico de Clausura de la Exposición "Cien años haciendo ciencia: la Cátedra de Hidrología Médica de la Facultad de Medicina de la Universidad Complutense (1912-2012)." y descubrimiento de lápida conmemorativa del centenario de la creación de la Cátedra de Hidrología Médica. Madrid 19/06/2012. (Figuras 1 y 2)

- Miembros del Comité Organizador

Figura 1 - Entrega de placa conmemorativa de la Sociedad Portuguesa de Hidrología Médica al Decano de la Facultad de Medicina. Profesores Álvarez-Sala y Cantista

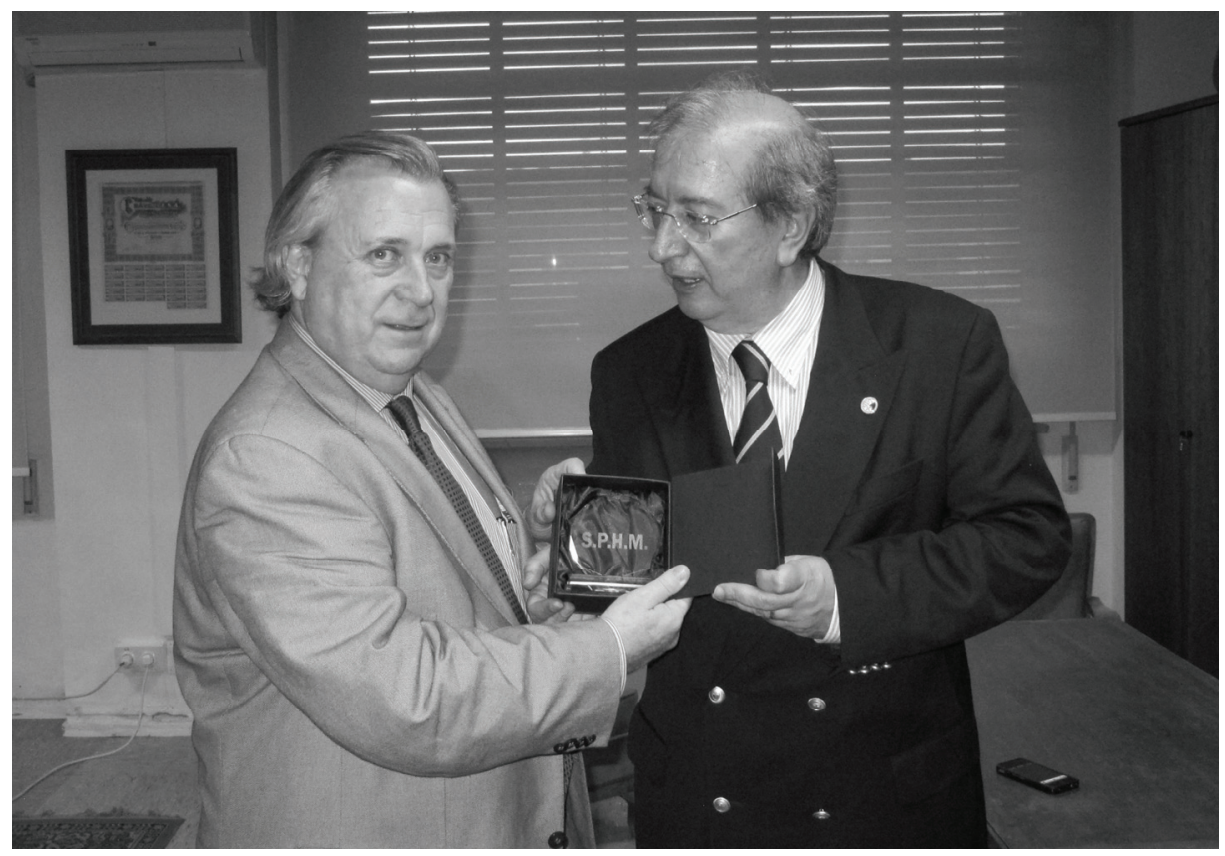

44. 38 World Congreso of the Internacional Society of Medical Hydrology and Climatology. Lanjarón (Granada) 20-23/06/2012.

- Presidencia del Comité Organizador

- Miembros del Comité Científico

- Presidencia de Sesiones 
Figura 2 - Lápida conmemorativa del centenario

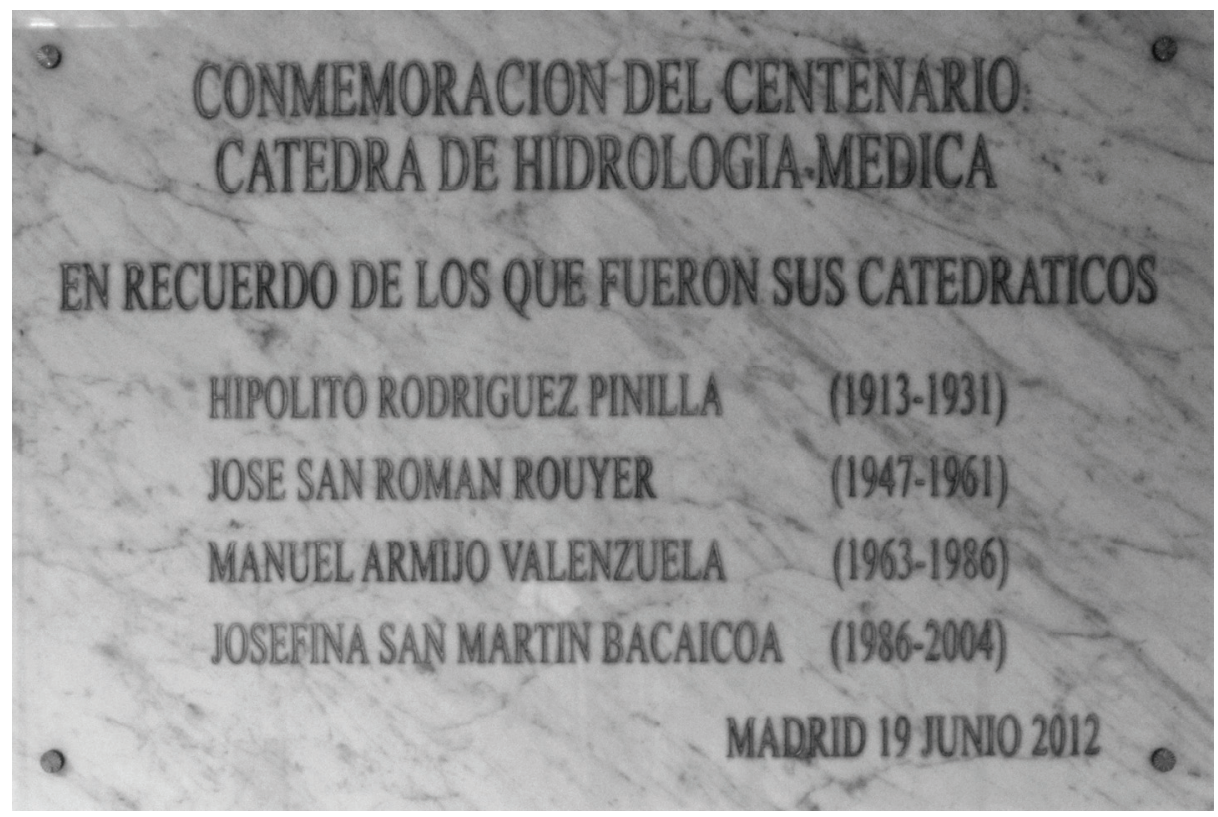

- Ponencias invitadas (6):

State of the art, Health Resort Medicine in Spain

Study of ciliary motility in patients treated with mineral waters from "Las Termas de Copahue", Neuquén, Argentina

Is thalassotherapy simply a type of climatotherapy? no, certainly, it's not

Biophysical skin effects of peloids according to their maturity time

The Bahia 2011 Seniors study. patterns of Hydration in the elderly in Spain

Water Journeys (II): Granada Spas and Springs through Travelers' and Hydrologists' eyes

- Comunicaciones orales (5):

Variation of the instrumental texture of peloids as a function of the water content Balneotherapy and mud-therapy in knee osteoarthritis treatment Nitrates in spanish waters: natural mineral water and tap water Cardiovascular risk factors in patients of the social thermal program in Lanjarón Spa

Balneology Research in Spain 
- Posters (10):

Spa, hydrotherapy's treatment, and quality of life

Quality of life and thermal cure

Thermotherapy applications in spanish resorts using peloids and parafangos

Study of the liquid phase of peloids prepared with mineral waters from balneario de Lanjarón (Granada, Spain)

Cardiorespiratory response to Thalassotherapy on stroke patients

Talassotherapy on stroke rehabilitation. Review of classical contraindications, complications. Comparison with a traditional Spa in Murcia

Beneficial effects of Thalassotherapy in upper limb hemiparesis after stroke

Health workers knowledge about medical hydrology in Spain

Health workers knowledge about medical hydrology in Argentina

Medico-legal aspects of the Medical Hydrology in Spain

45. Termatalia Perú - Encuentro Internacional sobre Agua y Termalismo. El CallaoLima (Perú) 27-30/09/2012.

- Director Científico

- Miembro del Comité Expertos

- Ponencias invitadas (3):

Introducción a la Hidrología Médica. Indicaciones y tratamientos con aguas mineromedicinales

Importancia del control analítico de las aguas minerales. Antecedentes y situación actual

Hidratación y Salud. Diferencias entre el agua mineral natural y el agua potable

\section{TESIS / PROYECTOS DIRIGIDOS}

\section{Tesis Doctorales dirigidas}

1. Eva Del Castillo Garrabou

"Estudio de las aguas minerales de la provincia de Toledo"

04-10-2002. Facultad de Medicina - UCM. Sobresaliente "Cum Laude"

2. Estrella Cuenca Giralde

"Influencia de la crenoterapia con aguas bicarbonatadas sulfatadas en el estrés oxidativo de una población balnearia"

25-04-2003. Facultad de Medicina - UCM. Sobresaliente "Cum Laude"

3. Irene Del Hoyo Oubiña

"Estudio sobre el tratamiento termal en el balneario de Puente Viesgo (Cantabria)"

25-11-2003. Facultad de Medicina - UCM. Sobresaliente "Cum Laude" 
4. Eva María Palacín Minguez

"Estudio de las aguas minerales de la provincia de Valladolid" 26-03-2004. Facultad de Medicina - UCM. Sobresaliente "Cum Laude"

5. Eduardo Navarro García

"Contribución al estudio de los balnearios de las Islas Canarias: aguas minerales de Firgas"

16-09-2004. Facultad de Medicina - UCM. Sobresaliente "Cum Laude"

6. Ma Concepción Serrano Moreno

"Estudio experimental sobre aspectos vegetativos de gérmenes en aguas mineromedicinales y siembra directa / filtración por membrana del agua del manantial e instalaciones crenoterápicas del Balneario de Alange"

24-09-2004. Facultad de Medicina - UCM. Sobresaliente "Cum Laude"

7. Concepción Cuenca González

"Los Anales Hispanoamericanos de Hidrología Médica y Climatología. Indización y juicio crítico (1954-1958)"

21-11-2005. Facultad de Medicina - UCM. Sobresaliente "Cum Laude"

8. Luis Perea Unceta

"Efecto del agua mineromedicinal de Carabaña en las Personas Mayores"

17-05-2006. Facultad de Medicina - UCM. Sobresaliente "Cum Laude"

9. Onica Armijo Suárez

"Estudio de los Peloides españoles"

06-09-2007. Facultad de Medicina - UCM. Sobresaliente "Cum Laude"

10. Ana María Monasterio Medicci

"Estudio de las aguas minerales de la provincia de Neuquén - República Argentina"

19-11-2010. Facultad de Medicina - UCM. Sobresaliente "Cum Laude"

\section{Diplomas de Estudios Avanzados}

1. Eva Bermejo García

El Balneario de Arnedillo "La Rioja" en la primera mitad del siglo XIX (1817-1850)

13-03-2002. Facultad de Medicina - UCM. Apto 
2. Esther Garrido Mayor

El Balneario de Archena "Murcia" en la primera mitad del siglo XIX (1829-1845)

13-03-2002. Facultad de Medicina - UCM. Apto

3. Blanca Herrero Salas

El Balneario de Solan de Cabras "Beteta-Cuenca" en la primera mitad del siglo XIX (1817-1861)

13-03-2002. Facultad de Medicina - UCM. Apto

4. César Morales Bayle

El Balneario de Alhama de Granada en la primera mitad del siglo XIX (1838-1857)

13-03-2002. Facultad de Medicina - UCM. Apto

5. Hernando Jimeno Barrios

Factores de riesgo cardiovascular en la población balnearia de Alange

24-06-2002. Facultad de Medicina - UCM. Apto

6. Tomás Ares Guimil

Turismo de Salud en la Sociedad de Ocio

24-06-2002. Facultad de Medicina - UCM. Apto

7. Miguel Ángel Fernández Torán

Gestión de la Calidad en Termalismo

24-06-2002. Facultad de Medicina - UCM. Apto

8. Laura Ortega Muniaín

Alhama de Aragón

24-06-2002. Facultad de Medicina - UCM. Apto

9. Onica Armijo Suarez

Curas hidrotermales ginecológicas en España

02-10-2002. Facultad de Medicina - UCM. Apto

10. Ma Isabel López Delgado

Estudio de la población balnearia de tipo lúdico en el Balneario de Lanjarón 02-10-2002. Facultad de Medicina - UCM. Apto

11. Oscar Luis Sosa Hernández

Los Berrazles

02-10-2002. Facultad de Medicina - UCM. Apto 
12. Armindo Custodio Mendoça Caetano Aguas Mineromedicinales Portuguesas en el Siglo XIX 03-07-2003. Facultad de Medicina - UCM. Apto

13. Eduardo Navarro García

Contribución al estudio de los balnearios de las Islas Canarias. Aguas minerales de Firgas

03-07-2003. Facultad de Medicina - UCM. Apto

14. Montserrat Capdevila Folguera

El Zinc en las Aguas Minero-Medicinales

03-07-2003. Facultad de Medicina - UCM. Apto

15. Nieves Hurtado de Mendoza

Análisis físico químico del agua de los Baños del Peral

03-07-2003. Facultad de Medicina - UCM. Apto

16. Concepción Cuenca González

Los Anales Hispanoamericanos de Hidrología Medica. Indización y juicio crítico ( 1954-1958)

07-10-2003. Facultad de Medicina - UCM. Apto

17. Concepción García Jordan

Real Balneario de Trillo (Guadalajara). Algunos apuntes

07-10-2003. Facultad de Medicina - UCM. Apto

18. Claudia Lía Urrego

Arqueología de los Baños Árabes de Ronda. Historia y entorno físico

07-10-2003. Facultad de Medicina - UCM. Apto

19. Carla Morer Liñán

El Níquel en las Aguas Minero-Medicinales Españolas

07-10-2003. Facultad de Medicina - UCM. Apto

20. Stamatia Polyziadis Voulodimos

Aguas de débil mineralización. Algunos Balnearios e indicaciones

07-10-2003. Facultad de Medicina - UCM. Apto

21. Ma Dolors Tenas i Bastida

Estudio analítico del cobre en las aguas mineromedicinales españolas

07-10-2003. Facultad de Medicina - UCM. Apto 
22. $\mathrm{M}^{\mathrm{a}}$ Ángela García Matas

Marketing Sanitario Termal. Apertura de Nuevos Mercados

07-07-2004. Facultad de Medicina - UCM. Apto

23. Paloma Tejero García

Creación de un área de medicina estética hidrotermal

07-07-2004. Facultad de Medicina - UCM. Apto

24. Sara Causapé García

Fuente del Chorrillo. Alhama de Aragón (Zaragoza)

09-10-2006. Facultad de Medicina - UCM. Apto

25. Carmen Rocío Escudero López

Los Baños del Tío Pedrilla

09-10-2006. Facultad de Medicina - UCM. Apto

26. Clemente Jiménez Parra

Baños de Perete. Análisis físico-químico y bacteriológico

09-10-2006. Facultad de Medicina - UCM. Apto

27. Roberto Maroto Cuadrado

Estudio del agua de la Fuente del Venero de la Isla y su entorno

09-10-2006. Facultad de Medicina - UCM. Apto

28. Mercedes Ponce de León Almira

Manantial Uberba

09-10-2006. Facultad de Medicina - UCM. Apto

29. Noemí Soriano Pascual

Boletines de la Sociedad Española de Hidrología Médica. Estudio descriptivo e indización (1986-1990)

09-10-2006. Facultad de Medicina - UCM. Apto

30. $\mathrm{M}^{\mathrm{a}}$ Dolores Vesga Marqués

Estudio analítico del agua del manantial de Sobrón

05-10-2007. Facultad de Medicina - UCM. Apto

31. Alfredo Arronte Alonso

Estudio analítico del agua de Solán de Cabras

23-09-2008. Facultad de Medicina - UCM. Apto 
32. Mariano Barcena Miguel

Estudio de las aguas del manantial de "El Montecillo" en Redueña (Madrid 23-09-2008. Facultad de Medicina - UCM. Apto

33. Mónica Rodríguez Fernández

Estudio sobre el manantial del Robledillo

23-09-2008. Facultad de Medicina - UCM. Apto

34. Aurora Santamaría Godoy

Estudio hidrológico e hidroterápico del manantial de Agua Agria de Paterna del Rio

23-09-2008. Facultad de Medicina - UCM. Apto

35. Luís Ovejero Ovejero

Sistema mecanizado para la elaboración, transporte y esterilización de peloides termales

23-09-2008. Facultad de Medicina - UCM. Apto

36. Víctor M Palencia Echevarría

Termalismo Infantil. Técnicas de aplicación

23-09-2008. Facultad de Medicina - UCM. Apto

37. Juan Andrés Barroso Fernández

Estudio analítico de las aguas mineromedicinales del Balneario de Archena y su aplicación

23-06-2009. Facultad de Medicina - UCM. Apto

38. Javier Guillermo Ubogui

Experiencia sobre tratamiento termal en pacientes con Psoriasis

23-06-2009. Facultad de Medicina - UCM. Apto

39. $\mathrm{M}^{\mathrm{a}}$ Lorena Vela Iglesias

Agua Mineral Natural envasada de Lanjarón. Un fascinante viaje desde una botella de agua a las tierras del agua

23-06-2009. Facultad de Medicina - UCM. Apto

40. Ana Maria Monasterio

Estudio analítico de las aguas minerales de laguna del Chancho. Cito en las Termas de Copahue -Neuquén- Republica Argentina.

25-09-2010. Facultad de Medicina - UCM. Apto 
41. Dany Olivier Cegarra

Estudio analítico del agua envasada de Jaraba

25-09-2010. Facultad de Medicina - UCM. Apto

42. Antonio Pedro Pinto Cantista

El Termalismo en Portugal

30-06-2010. Facultad de Medicina - UCM. Apto

43. José M. Carbajo Espejo

Modificación de las características biofísicas de la piel por aplicación de cosmético a base de peloides de aguas mineromedicinales 30-06-2010. Facultad de Medicina - UCM. Apto

44. Elisa Párraga de las Marinas

Estudio analítico de las aguas mineromedicinales del balneario de San Andrés de Canena (Jaén)

30-06-2010. Facultad de Medicina - UCM. Apto

45. Enrique Piedras Vidal

Antecedentes históricos de la Isla de la Toja

30-06-2010. Facultad de Medicina - UCM. Apto

46. Marcos Untura Filho

Valoración del tratamiento Termal de la Gonartrosis de Rodillas en las Thermas Antonio Carlos. Poços de Caldas - Estado de Minas Gerais. Brasil 30-06-2010. Facultad de Medicina - UCM. Apto

47. Isabel Lorente Alcaraz

Sistemas de calidad de servicios. Adaptación del manual de servicio Qualicert® "Talasoterapia" a "Balneoterapia": nuestra experiencia

22-09-2010. Facultad de Medicina - UCM. Apto

48. Xavier Marí i Cerezo

Valoración funcional de la marcha en pacientes con fibromialgia tras el tratamiento en el balneario de Chulilla

22-09-2010. Facultad de Medicina - UCM. Apto 


\section{OTRAS ACTIVIDADES}

\section{ACUERDOS MARCOS DE COLABORACIÓN}

1. Universidad Complutense de Madrid - Instituto de Salud Carlos III Asociación Nacional de Estaciones Termales

Fecha: 03-12-2001

2. Universidad Complutense de Madrid - Laboratorios Quinton Internacional, SL

Fecha: 11-11-2003

3. Universidad Complutense de Madrid - Ministerio de Producción y Turismo del Neuquén (Ente Provincial Termas del Neuquén ENPROTERN)

Fecha: 31-03-2006

4. Universidad Complutense de Madrid - Asociación Nacional de Aguas de Bebida Envasadas (ANEABE)

Fecha: 07-05-2007

5. Universidad Complutense de Madrid - Universidad Víctor Segalen Burdeos-2 (Instituto de Termalismo de Dax)

Fecha: 08-06-2007

6. Universidad Complutense de Madrid - Asociación Nacional de Balnearios (ANBAL)

Fecha: 22-06-2007

7. Universidad Complutense de Madrid - Font Vella y Lanjarón, SA Fecha: 18-02-2008

8. Universidad Complutense de Madrid - Chaplan, SA (Balneario Aguas de Carabaña)

Fecha: 30-04-2008

9. Universidad Complutense de Madrid - Asociación Brasileña de Industria de Aguas Minerales (ABINAM)

Fecha: $18-10-2010$ 
10. Universidad Complutense de Madrid - Asociación de Termalismo de Andalucía

Fecha: 29-10-2010

\section{CONVENIOS ESPECÍFICOS DE PRÁTICAS}

Para la realización de las prácticas rotatorias en establecimientos balnearios y centros de talasoterapia de los Médicos Internos Residentes de la Escuela, la Universidad ha establecido Convenios Específicos de prácticas con treinta y tres Centros Termales que detallamos: en Andalucía, Balneario de Lanjarón (Granada), Gran Hotel Elba Estepona Talaso Spa (Málaga); en Aragón, Balneario Sicilia (Zaragoza), Balneario Termas Pallarés (Zaragoza); en Canarias, Talasoterapia las Canteras (Gran Canarias); en Cantabria, Balneario de La Hermida (Santander), Balneario de Liérganes (Santander), Balneario de Puente Viesgo (Santander), Balneario de Solares (Santander); en Castilla-León, Balneario de Ledesma (Salamanca), Balneario Palacio de las Salinas (Valladolid), Balneario Villa de Olmedo (Valladolid); en Castilla-La Mancha, Balneario de Cervantes (Ciudad Real); en Cataluña, Balneario Blancafort (Barcelona), Termas Victoria (Barcelona); en Extremadura, Balneario de Baños de Montemayor (Cáceres), Balneario de Alange (Badajoz); en Galicia, Balneario de Arnoia (Ourense), Balneario de Laias (Ourense), Balneario de Lobios (Ourense), Termas de Cuntis (Pontevedra), Balneario Gran Hotel la Toja (Pontevedra), Balneario Isla de la Toja (Pontevedra), Balneario de Mondariz (Pontevedra), Talaso Louxo La Toja (Pontevedra); en la Comunidad de Murcia, Archena (Murcia), Balneario Fortuna-Leana (Murcia), Thalassia (Murcia); en Navarra, Balneario de Fitero (Pamplona); en el País Vasco, Balneario de Cestona (Guipuzcoa); en la Comunidad Valenciana, Balneario de Montanejos (Castellón), Termas Marinas de Benicasin (Castellón), Hervideros de Cofrentes (Valencia) y en Francia con el Establecimiento Termal de La Roche-Posay.

\section{VISITAS DE ESTUDIOS CON LOS ALUMNOS}

Durante los diferentes Cursos Académicos se han realizado visitas de estudios con los Alumnos a cincuenta y seis Centros Termales que paso a detallar: en Andalucía, Balneario de Alicun de las Torres (Granada), Balneario de Lanjarón (Granada), Balnearios de San Andrés de Canena (Jaén); en Aragón, El Paraíso (Teruel), Balneario Baños de Serón (Zaragoza), Balneario de Paracuellos de Jiloca (Zaragoza), Balneario San Roque (Zaragoza), Balneario Sicilia (Zaragoza), Balneario Termas Pallarés (Zaragoza), Balneario La Virgen (Zaragoza); en Cantabria, Balneario de Alceda (Santander), Balneario de las Caldas de Besaya (Santander), Balneario de La Hermida (Santander), Balneario de Liérganes (Santander), Balneario de Puente Viesgo (Santander), Balneario de Solares (Santander); en Castilla-León, Balneario de Corconte (Burgos), Balneario de Valdelateja (Burgos), Balneario de Ledesma 
(Salamanca), Balneario de Retortillo (Salamanca), Balneario Palacio de las Salinas (Valladolid), Balneario Villa de Olmedo (Valladolid); en Castilla-La Mancha, Balneario de Tus (Albacete), Balneario Baños de Benito (Ciudad Real), Balneario Baños de La Concepción (Ciudad Real), Balneario Baños de La Esperanza (Ciudad Real), Balneario de Cervantes (Ciudad Real), Trillo (Guadalajara); en Cataluña, Balneario Caldes de Boí (Lleida), Balneario de Vallfogona de Riucorb (Tarragona); en Extremadura, Balneario de Baños de Montemayor (Cáceres), Balneario El Salugral (Cáceres), Balneario Valle del Jerte (Cáceres), Balneario de Alange (Badajoz); en Galicia, Balneario Aguas Santas de Panton (Lugo), Termas Romanas de Lugo (Lugo), Balneario de Arnoia (Ourense), Balneario Baños de Molgas (Ourense), Balneario de Laias (Ourense), Balneario de Lobios (Ourense), Termas de Cuntis (Pontevedra), Talaso Atlantico (Pontevedra), Balneario Gran Hotel la Toja (Pontevedra), Balneario Isla de la Toja (Pontevedra), Balneario de Mondariz (Pontevedra), Talaso Louxo La Toja (Pontevedra); en la Comunidad de La Rioja, Arnedillo (Logroño); en la Comunidad de Madrid, Balneario de Carabaña (Madrid); en la Comunidad de Murcia, Archena (Murcia), Balneario Fortuna-Leana (Murcia), Thalasia (Murcia); en Navarra, Balneario de Fitero (Pamplona); en el País Vasco, Balneario de Cestona (Guipuzcoa); en la Comunidad Valenciana, Laboratorios Quinton (Alicante), Balneario de Montanejos (Castellón), Marina D’Or (Castellón), Termas Marinas de Benicasin (Castellón), Balneario de Chulillas (Valencia), Balneario de Fuente Podrida (Valencia), Balneario de Hervideros de Cofrentes (Valencia), Balneario de Verches (Valencia) y en Francia las Villas Termales de Bagneres de Luchon y Dax.

\section{ESTUDIO ANALÍTICO DE AGUAS MINEROMEDICINALES}

En el período señalado se ha analizado noventa y cinco aguas mineromedicinales que son: en Andalucía, Balneario Alhama de Granada, Balneario de Alicun de las Torres, Balneario Fuente Amarga, Balneario de Graena, Balneario de La Malahá, Balneario de Lanjarón, Balnearios de San Andrés, Balneario San Nicolás, Balneario de Sierra Alhamilla, Balneario de Tolox; en Aragón, Baños de Benasque, Balneario de Panticosa, Balneario de Paracuellos de Jiloca, Balneario El Paraíso, Balneario San Roque, Balneario Baños de Serón, Balneario Sicilia, Balneario Termas Pallarés, Balneario Vilas del Turbón, Balneario La Virgen; en Asturias, Caldas de Oviedo; en Baleares, Balneario San Juan de la Font Santa; en Canarias, Balneario Pozo de la Salud; en Cantabria, Balneario de Alceda, Balneario de las Caldas de Besaya, Balneario de La Hermida, Balneario de Liérganes, Balneario de Puente Viesgo, Balneario de Solares; en Castilla-La Mancha, Balneario de Alcantud, Balneario Baños de Benito, Balneario de Cervantes, Balneario de la Concepción, Balneario de la Esperanza, Balneario de Fuencaliente, Balneario Solán de Cabras, Trillo, Balneario de Tus; en Castilla-León, Balneario de Almeida, Balneario de Corconte, Balneario de Ledesma, Balneario Caldas de Luna, Balneario Palacio de las Salinas, Bal- 
neario de Retortillo, Balneario de Valdelateja, Balneario Villa de Olmedo; en Cataluña, Balneario Baños de Tredós, Balneario Blancafort, Balneario Broquetas, Balneario Caldes de Boí, Balneario Caldes d'Estrac, Balneario Codina, Balneario Comaruga, Balneario Font Vella, Balneario Termas la Garriga, Balneario Termas Montbrió, Balneario Termas Orión, Balneario Termas Victoria, Balneario Prats, Balneario San Vicente de Torelló, Balneario Titus, Balneario de Vallfogona de Riucorb, Balneario Vichy Catalan, Balneario Vila de Caldes; en Extremadura, Balneario de Alange, Balneario de Baños de Montemayor, Balneario El Raposo, Balneario El Salugral, Balneario de San Gregorio de Brozas, Balneario Fuentes del Trampal, Balneario Baños de Valdefernando, Balneario Valle del Jerte; en Galicia, Balneario Aguas Santas de Panton, Balneario de Acuña, Balneario de Arnoia, Balneario de Arteixo, Balneario Baños Da Brea, Balneario Caldas de Partovia, Balneario Caldelas de Tuy, Balneario de Carballino, Balneario Baños Viejos de Carballo, Balneario Termas de Cuntis, Balneario Dávila, Balneario de Guitiriz, Balneario de La Toja, Balneario de Laias, Balneario de Lobios, Balneario de Lugo, Balneario Baños de Molgas, Balneario de Mondariz, Balneario $\mathrm{N}^{\mathrm{a}} \mathrm{S}^{\mathrm{a}}$ de los Ángeles, Balneario Rio Pambre; en la Comunidad de La Rioja, Balneario de Arnedillo; en la Comunidad de Madrid, Balneario de Carabaña; en la Comunidad de Murcia, Balneario de Archena, Balneario Fortuna-Leana; en Navarra, Balneario Baños de Fitero; en el País Vasco, Balneario de Cestona, Balneario Molinar de Carranza; en la Comunidad Valenciana, Balneario de la Alameda, Balneario de Chulillas, Balneario de Fuente Podrida, Balneario de Hervideros de Cofrentes, Balneario de Montanejos, Balneario de Verches y Agrupación de balnearios de Villavieja.

\section{ESTUDIO ANALÍTICO DE AGUAS MINERALES NATURALES}

En estos años se han analizado ciento doce aguas minerales naturales, noventa y nueve nacionales y trece extranjeras. Entre las primeras: Agua de Bejis, Agua de Beteta, Agua de Bronchales, Agua de Chovar, Agua de Cuevas, Agua de Sousas, Agua del Rosal, Aguadoy, Aguas de Manzanera, Aguasana, Aiguaneu, Alzola, Aqua Nevada, Aquabona Fontoira, Aquabona Fuen-Mayor, Aquabona Santolín, Aquadeus, Aquarel-Las Jaras, Aquarel-Los Abetos, Babilafuente, Belascoaín, Betelu, Bezoya Trescasas, Borines, Cabreiroá con gas, Cabreiroá sin gas, Calabor, Caldes de Bohi, Carrizal II, Corconte, Cortes, El Cañar, Font del Regàs, Font Natura, Font Nova del Pla, Font Sol, Font Vella Sacalm, Font Vella Sigüenza, Fontdor, Fontecabras, Fontecelta, Fontedoso, Fonteide, Fontenova con gas, Fontenova sin gas, Fonter, Fontxesta, Fuencisla, Fuensanta, Fuente del Val, Fuente Estrella, Fuente Liviana- Arroyo de la Hoz, Fuente Liviana- Serranía I, Fuente Madre, Fuente Primavera, Fuentelajara, Fuentes de Lebanza, Fuentevera, Insalus, La Ideal II, Lanjarón Fonteforte, Lanjarón Salud, Les Creus, Los Escudos, Los Riscos, Lunares, Malavella, Manantial Ballanes, Manantial Fontboix, Mondariz, Montepinos, Natura, Neval, Pascual Nature Camporrobles, Pascual Nature Los Barrancos, Peñaclara, 
Ribes, Rocallaura, San Andrés II, San Antón II, San Joaquín, San Millán, San Narciso, Sant Aniol, Sierra de Cazorla, Sierra de Segura, Sierra del Aguila, Sierra Dúrcal, Sierra Fría, Solán de Cabras, Solares, Teleno, Valtorre, Veri I, Veri V, Vichy Catalán, Viladrau, Vilajuïga y Vilas del Turbón. Entre las segundas: Agua Panna, Badoit, Evian, Jouvence de Wattwiller, Pedras Salgadas, Perrier, San Martino, San Pellegrino, Saint Géron, Ty Nant, Vichy-Célestins, Vittel y Volvic.

\section{ESTUDIO DE PROPIEDADES FÍSICO-QUÍMICAS DE PELOIDES}

Se ha realizado el estudio de los peloides empleados en los siguientes Centros Termales: Balneario de Archena (Murcia), Balneario de Arnedillo (La Rioja), Balneario de Caldes de Bohí (Lleida), Balneario el Raposo (Badajoz), Lopagán (Murcia), Thalasia (Murcia), Centro Terdax (Dax - Las Landas. Francia), Poço de Caldas (Minas Gerais - Brasil) y Copahue (Neuquén - Argentina).

\section{AGRADECIMIENTOS}

A todos los profesores de la Cátedra de Hidrología Médica que nos han facilitado sus currículos para la elaboración de esta memoria, especialmente a la Profesora Josefina San Martín Bacaicoa que gentilmente ha puesto a nuestra disposición su "Curriculum Vitae para el nombramiento de Profesor Emérito, 2004 Mar 20; Madrid Universidad Complutense".

Así como, a las personas que, durante este periodo, nos han ayudado diariamente en nuestro trabajo: Izaskun Hurtado, Mari Luz Marina, Manoli Uceda y Cecilia Rodríguez-Bartolomé. 


\section{ÍNDICE DE LA MEMORIA DE ACTIVIDADES}

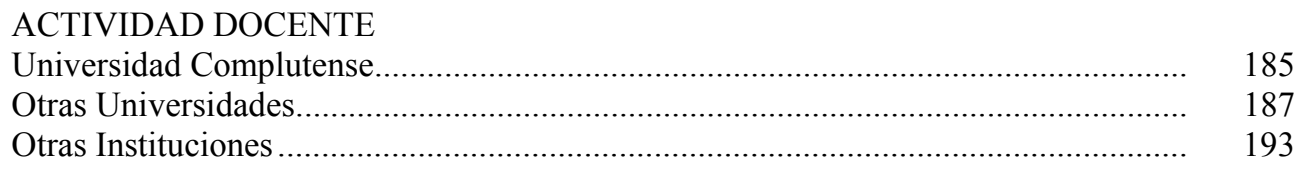

ACTIVIDAD INVESTIGADORA

PROYECTOS Y CONTRATOS

Financiados en convocatoria pública

Contratos con empresas y/o administraciones ..................................................... 198

PUBLICACIONES

Revistas científicas nacionales

Revistas científicas internacionales .................................................................... 211

Libros y capítulos de libro .............................................................................. 213

Congresos y reuniones científicas nacionales..................................................... 216

Congresos y reuniones científicas internacionales ............................................... 222

CONTRIBUCIONES A CONGRESOS

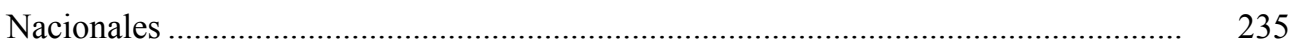

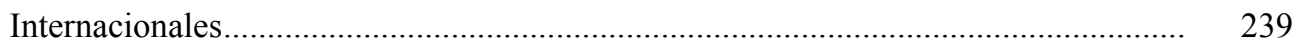

TESIS / PROYECTOS DIRIGIDOS

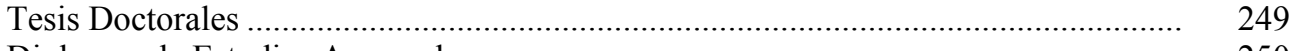

Diplomas de Estudios Avanzados ....................................................................... 250

OTRAS ACTIVIDADES

Acuerdos Marcos de Colaboración....................................................................... 256

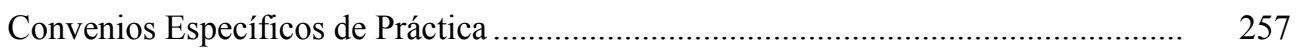

Visitas de estudios con alumnos ....................................................................... 257

Estudios analítico de aguas mineromedicinales..................................................... 258

Estudios analítico de aguas minerales naturales ........................................................ 259

Estudios de propiedades físico-químicas de peloides ............................................. 260

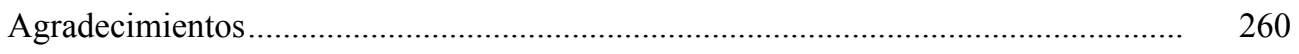

